\title{
Global Water, Sanitation, and Hygiene Research Priorities and Learning Challenges under Sustainable Development Goal 6
}

\author{
Karen Setty ${ }^{1}$, Alejandro Jiménez ${ }^{2}$, Juliet Willetts ${ }^{3}$, Mats Leifels ${ }^{4}$ and Jamie Bartram ${ }^{5}$
}

\begin{abstract}
Motivation: Sanitation and Water for All (SWA) is a global partnership addressing challenges to universal water, sanitation, and hygiene (WaSH) access. Shortly following adoption of the United Nations' Sustainable Development Goals, the Research and Learning (R\&L) constituency of SWA undertook a systematic study to determine global research priorities and learning needs.

Purpose: We aimed to identify priority topics where improved knowledge would aid achievement of Goal 6, by developing a global WaSH research agenda, and to describe evidenceuse challenges among WaSH professionals.
\end{abstract}

Approach and Methods: We delivered a tailored, semi-structured electronic questionnaire to representatives from countries, R\&L institutions, and other SWA partners (external support agencies, civil society, and private sector). The survey gathered views from 76 respondents working in an estimated 36 countries across all world regions. Data were analyzed quantitatively and qualitatively to identify patterns and themes.

Findings: Most responses indicated lowered confidence on at least one Goal 6 target area, especially managing untreated wastewater and faecal sludge. Both brief and lengthy information formats were valued. WaSH information was perceived as conflicting or unreliable among non-R\&L constituencies, suggesting differences in perceptions and information-seeking approaches. While the R\&L constituency appeared saturated with learning and training

${ }^{1}$ The Water Institute at University of North Carolina at Chapel Hill, Department of Environmental Sciences and Engineering, 166 Rosenau Hall, CB \#7431, Chapel Hill, NC 27599-7431. Corresponding author. Email: ksetty@live.unc.edu

${ }^{2}$ Stockholm International Water Institute (SIWI), Linnégatan 87A, Box 101 87, 10055 Stockholm, Sweden

${ }^{3}$ University of Technology Sydney, Institute for Sustainable Futures, Bldg 10, 235 Jones St, Ultimo NSW 2007, Australia

${ }^{4}$ Centre for Water and Environmental Research (ZWU), University Duisburg-Essen, Universitätsstr. 2, 45141, Essen, Germany and University of Alberta, School of Public Health, 3-300 Edmonton Clinic Health Academy, 11405 - 87 Ave, Edmonton, AB T6G 1C9, Canada

${ }^{5}$ The Water Institute at University of North Carolina at Chapel Hill, Department of Environmental Sciences and Engineering, 166 Rosenau Hall, CB \#7431, Chapel Hill, NC 27599-7431

This article has been accepted for publication and undergone full peer review but has not been through the copyediting, typesetting, pagination and proofreading process, which may lead to differences between this version and the Version of Record. Please cite this article as

doi: $10.1111 /$ dpr.1200

This article is protected by copyright. All rights reserved. 
opportunities, others perceived barriers to participating (e.g. not receiving notice or invitation). Research and other WaSH activities were frequently constrained by upward accountability to funders, while stakeholders were inconsistently included in research processes.

Policy implications: This study offers insight into perceived research and decision challenges related to Goal 6 targets. It develops a unified research agenda focused on high priority topics, and recommends renewed attention to evidence synthesis, learning and implementation support, research engagement, and multisectoral coordination.

\section{Key Words}

SDG, WaSH, Capacity Building, Science-Policy Interface, Research Translation

\section{Introduction}

The United Nations (UN) Sustainable Development Goals (SDGs) replaced the Millennium Development Goals (MDGs) at the end of 2015 (UN General Assembly, 2015). Among the 17 SDGs, Goal 6 seeks to 'ensure availability and sustainable management of water and sanitation for all'. Although some components of other SDGs also address or intermix with water, sanitation, and hygiene (WaSH), the Goal 6 targets in particular set out a clear agenda that will play an important role in framing WaSH development efforts from 2015 to 2030 (UN, 2018). In comparison to the previous MDG target 7.C: 'halve, by 2015, the proportion of the population without sustainable access to safe drinking water and basic sanitation' (UN, 2015), SDG 6 is more ambitious and may demand a shift in knowledge needs, potentially leaving WaSH professionals and institutions under-prepared.

This transition represented an opportune time for WaSH professionals to reflect on what activities might best support global achievement of Goal 6, as well as what factors might hinder its realization. While access to water and sanitation services has expanded over recent decades, progress has been hampered by population growth, among other factors, leaving many unserved or underserved (World Health Organization \& UNICEF, 2014). Inadequate water supplies and poor sanitation and hygiene continue to contribute to disease and deaths, especially in low-income countries and among children under five (Troeger et al., 2017; Wolf et al., 2018). Efforts to improve these conditions are plagued by multiple challenges, including

This article is protected by copyright. All rights reserved. 
weak political support, insufficient national capacity, gaps in monitoring, and inadequate human resources (WASH Impact Network, n.d.; World Health Organization \& UNICEF, 2014).

Sanitation and Water for All (SWA) was established in 2009, in part to address inefficiencies in WaSH sector coordination and to drive progress towards the MDGs. This global partnership of more than 170 entities works together to catalyse political leadership and action, improve accountability, and use scarce resources more effectively within the WaSH arena (SWA, 2018). Partners agree to work towards a common vision of universal access to clean water and adequate sanitation. The growing SWA membership consists of diverse WaSH organizations, including civil society organizations (CSOs), national governments, multilaterals, development banks, foundations, private businesses, universities, and institutions. They typically join one of five SWA 'constituencies': countries, external support agencies, civil society, research and learning (R\&L), or the private sector.

SWA's R\&L partners commit to strengthening the evidence base for WaSH (SWA, 2018). Country partners represent low and middle-income country governments supporting domestic implementation of WaSH goals. Other SWA partners mobilize and allocate WaSH resources, influence political agendas, implement WaSH programmes or projects from regional to international levels, and/or conduct business that supports SWA objectives. SWA's three 'priority areas' are political prioritization, government-led national planning processes, and development of a strong evidence base (SWA, 2018). For the latter, SWA recognizes that decision-makers require high quality, up-to-date information to make appropriate and timely decisions.

Though linking scientific evidence to policy and practice outcomes is a common goal (Hering, 2018; Nutley, Walter, \& Davies, 2007), achieving this is challenging. Researchers often favour 'supply-driven' knowledge transfer, even when policy and practice needs are not adequately met, at the same time perceiving 'demand-driven' models as excessively constraining (Hering, 2018). Urging researchers to satisfy only client needs may compromise the scientific process and objectivity (Poch, Comas, Cortés, Sànchez-Marrè, \& Rodríguez-Roda, 2017). Further, needs assessment may inadvertently truncate agendas if it focuses on the most achievable short-term

This article is protected by copyright. All rights reserved. 
needs at the expense of long-term and sometimes more critical issues (Boyd, 2016). Timelines frequently differ, leading to a mismatch of research cycles with 'policy windows' (Rose et al., 2017). More structured approaches for harvesting evidence requirements and integrating them into research agendas (Huberman, 1994; Viergever, Olifson, Ghaffar, \& Terry, 2010), along with professional capacity building for 'boundary work' (Cash et al., 2003), could enhance progress toward WaSH goals.

Considering historic challenges and the diversity of WaSH actors worldwide, broad representation of stakeholders from multiple disciplines should feed into research prioritization (Bryant, Sanson-Fisher, Walsh, \& Stewart, 2014); however, some gaps stem from differences in norms of practice among actors. Policy-makers and their senior advisors have the closest interactive experience with how evidence informs decisions in their home countries, but may not be fully aware of their own future needs, or able to communicate them to researchers. Private businesses and CSOs often carry out WaSH projects, and gain familiarity with local context. In contrast, researchers often have more exposure to broad evidence and theory, but may be constrained by academic expectations, wherein funding availability and scientific advancement might take precedence over meeting the needs of end users (DFID, n.d.-a, n.d.-b; Kolsky, n.d.; Smith, An, \& Kawachi, 2013).

This study aimed to develop a global WaSH research agenda as collective guidance (e.g. for matching information needs to scientific bodies capable of fulfilling those needs). It also examined similarities and differences in perspectives among SWA constituencies to explore effective means for science communication and knowledge integration. Research questions asked:

1. What evidence would accelerate progress on Goal 6 ?

2. What type of evidence resources and delivery methods best support WaSH decisionmaking, research, or programme activities?

3. Which barriers limit WaSH decision-making, research, or programme activities?

4. How do respondent characteristics affect responses?

\section{Methods}

This article is protected by copyright. All rights reserved. 
Overall, this study sought to backward-map research priorities critical to the pursuit of Goal 6, to draw out knowledge gaps and barriers, and to identify valued information resources and patterns of evidence use across SWA constituencies. Practically, this meant inferring needs based on recent experiences or activities rather than asking participants to anticipate future needs. An electronic survey was the primary mode of data collection, and questionnaires were developed using pragmatic, stakeholder-driven procedures (Lewis, Weiner, Stanick, \& Fischer, 2015). The first questionnaire targeted representatives of SWA partner countries. Tailored questionnaires then solicited feedback from other SWA partners, including (a) researchers, and (b) 'all others' (multilaterals, private businesses, CSOs, and funders). To facilitate follow-up, an in-depth interview guide (not shown) was developed, pilot-tested, and revised in parallel, lending some initial insight to the overall approach to survey question development.

\section{Survey Development, Testing, and Translation}

The survey consisted of an electronic questionnaire tailored to each of the three constituency groupings and developed using Qualtrics software. Each began with brief background and consent information, followed by introductory text citing some key differences between the MDGs and SDGs. Depending on constituency, the questionnaires consisted of either five or six sections moving from research priorities to decision challenges, learning challenges, funding and stakeholder interactions, and finally respondent characteristics. At the conclusion of the questionnaires, all respondents had the option to provide a first name and method of contact for follow-up, as well as to nominate a potential new R\&L constituency member as part of an ongoing recruitment effort focused on institutions in the global South.

Survey questions and response categories (detailed in supplementary information) mirrored the research questions. Table 1 gives the country constituency survey as an example, while the R\&L and other questionnaires followed a similar format with minor modifications (described below). Questions sought to avoid unnecessary analytical leaps, focusing on recent personal experience. They sought both qualitative and quantitative information that could help describe important themes. Questionnaires comprised primarily closed-ended multiple-choice questions, typically with an 'other' write-in option, followed by an open-ended question to request elaboration and conclude each section. This combination of question types offered respondents suggestions for

This article is protected by copyright. All rights reserved. 
faster cognitive processing, while enabling free response to avoid limiting them to the suggested categories. The first question, for example, closely matched the Goal 6 targets (Table 2), while the second question requested open description of any specific knowledge gaps or areas of concern.

Table 1. Research questions mapped to country constituency questionnaire (full text offered as supplementary information)

\begin{tabular}{|c|c|c|c|}
\hline Research Question & $\begin{array}{l}\text { Information } \\
\text { Sought }\end{array}$ & Survey Section & Survey Questions \\
\hline \multirow[t]{2}{*}{$\begin{array}{l}\text { 1. What evidence } \\
\text { would accelerate } \\
\text { progress on Goal } 6 \text { ? }\end{array}$} & \multirow[t]{2}{*}{$\begin{array}{l}\text { Ranking of } \\
\text { uncertainties } \\
\text { and description } \\
\text { of knowledge } \\
\text { gaps }\end{array}$} & $\begin{array}{l}\text { 1. Introduction } \\
\text { and Targets }\end{array}$ & $\begin{array}{l}\text { How confident are you in your } \\
\text { knowledge and ability to work in each } \\
\text { of the following target areas of Goal } \\
6 \text { ? } \\
\text { Do you have any specific knowledge } \\
\text { gaps or areas of concern related to } \\
\text { achieving Goal } 6 \text { ? }\end{array}$ \\
\hline & & $\begin{array}{l}\text { 2. Information } \\
\text { for Decision- } \\
\text { Making }\end{array}$ & $\begin{array}{l}\text { When you made WaSH-related } \\
\text { decisions over the past six months, in } \\
\text { which of these areas (related to } \\
\text { governance and human resources OR } \\
\text { finance and information systems OR } \\
\text { technical areas) would more } \\
\text { information have been helpful? } \\
\text { What was the primary topic } \\
\text { of the WaSH-related decision (or } \\
\text { decisions) you made over the past six } \\
\text { months? }\end{array}$ \\
\hline $\begin{array}{l}\text { 2. What type of } \\
\text { evidence resources and } \\
\text { delivery methods best } \\
\text { support WaSH decision } \\
\text { making, research, or } \\
\text { programme activities? }\end{array}$ & $\begin{array}{l}\text { Ranking and } \\
\text { description of } \\
\text { preferred } \\
\text { information } \\
\text { sources and } \\
\text { formats }\end{array}$ & $\begin{array}{l}\text { 4. Approaches } \\
\text { to Gathering } \\
\text { Information }\end{array}$ & $\begin{array}{l}\text { Which organizations typically } \\
\text { offer useful (e.g., accessible, } \\
\text { understandable, relevant, and/or } \\
\text { sufficient) information for addressing } \\
\text { your WaSH-related questions? } \\
\text { Which actions or informational formats } \\
\text { are typically useful for addressing } \\
\text { your WaSH-related questions? } \\
\text { What would make the WaSH-related } \\
\text { information you accessed over the } \\
\text { past six months more useful? } \\
\text { What new resources, if any, would you } \\
\text { like to have available for addressing } \\
\text { your WaSH-related questions? }\end{array}$ \\
\hline
\end{tabular}

This article is protected by copyright. All rights reserved. 


\begin{tabular}{|l|l|l|l|}
\hline $\begin{array}{l}\text { 3. Which barriers limit } \\
\text { WaSH decision-making, } \\
\text { research, or } \\
\text { programme activities? }\end{array}$ & $\begin{array}{l}\text { Prevalence of } \\
\text { challenges } \\
\text { related to } \\
\text { information } \\
\text { versus other } \\
\text { aspects of } \\
\text { decision- } \\
\text { making }\end{array}$ & $\begin{array}{l}\text { 3. Limitations } \\
\text { to Decision- } \\
\text { Making }\end{array}$ & $\begin{array}{l}\text { Which (informational OR other) } \\
\text { challenges did you experience when } \\
\text { seeking information to make WaSH- } \\
\text { related decision(s) over the past six } \\
\text { months? } \\
\text { Based on these limitations, what } \\
\text { knowledge or information might have } \\
\text { helped with your decision(s)? }\end{array}$ \\
\cline { 2 - 4 } & $\begin{array}{l}\text { 5. Learning and } \\
\text { Training Needs }\end{array}$ & $\begin{array}{l}\text { Which challenges did you experience } \\
\text { when seeking WaSH-related training } \\
\text { or educational opportunities over the } \\
\text { past six months? } \\
\text { How willing would you be to interact } \\
\text { with WaSH researchers (e.g. to help } \\
\text { plan studies and share new } \\
\text { information)? }\end{array}$ \\
\hline $\begin{array}{l}\text { 4. How do respondent } \\
\text { characteristics affect } \\
\text { responses? }\end{array}$ & $\begin{array}{l}\text { Constituency } \\
\text { membership, } \\
\text { educational } \\
\text { field }\end{array}$ & $\begin{array}{l}\text { G. Your } \\
\text { Professional } \\
\text { Background }\end{array}$ & $\begin{array}{l}\text { specialization? } \\
\text { Which category best describes your } \\
\text { current workplace and professional } \\
\text { responsibilities? }\end{array}$ \\
\hline
\end{tabular}

Table 2. Example of question development based on Goal 6 target areas

\begin{tabular}{|c|c|}
\hline Text of Goal 6 and targets (UN, 2018) & Text of final survey question \\
\hline $\begin{array}{l}\text { Goal 6: Ensure availability and sustainable } \\
\text { management of water and sanitation for all }\end{array}$ & $\begin{array}{l}\text { Q1. How confident are you in your } \\
\text { knowledge/ability to work in each of the } \\
\text { following target areas of Goal } 6 \text { ? }\end{array}$ \\
\hline $\begin{array}{l}\text { 6.1. By } 2030 \text {, achieve universal and equitable access } \\
\text { to safe and affordable drinking water for all }\end{array}$ & $\begin{array}{l}\text { A) Achieving universal access } \\
\text { B) Improving levels of service }\end{array}$ \\
\hline $\begin{array}{l}\text { 6.2. By 2030, achieve access to adequate and } \\
\text { equitable sanitation and hygiene for all and end open } \\
\text { defecation, paying special attention to the needs of } \\
\text { women and girls and those in vulnerable situations }\end{array}$ & $\begin{array}{l}\text { C) Addressing inequalities among sub- } \\
\text { populations } \\
\text { D) Ending open defaecation }\end{array}$ \\
\hline $\begin{array}{l}\text { 6.3. By } 2030 \text {, improve water quality by reducing } \\
\text { pollution, eliminating dumping and minimizing } \\
\text { release of hazardous chemicals and materials, halving } \\
\text { the proportion of untreated wastewater and } \\
\text { substantially increasing recycling and safe reuse } \\
\text { globally }\end{array}$ & E) Managing untreated wastewater \\
\hline $\begin{array}{l}\text { 6.4. By } 2030 \text {, substantially increase water-use } \\
\text { efficiency across all sectors and ensure sustainable } \\
\text { withdrawals and supply of freshwater to address } \\
\text { water scarcity and substantially reduce the number } \\
\text { of people suffering from water scarcity }\end{array}$ & $\begin{array}{l}\text { (Omitted from Q1 for brevity after pilot } \\
\text { testing; write-in option under Q2: Do you } \\
\text { have any specific knowledge gaps or areas of } \\
\text { concern related to achieving Goal 6?) }\end{array}$ \\
\hline
\end{tabular}

This article is protected by copyright. All rights reserved. 


\begin{tabular}{|l|l|}
\hline $\begin{array}{l}\text { 6.5. By 2030, implement integrated water resources } \\
\text { management at all levels, including through } \\
\text { transboundary cooperation as appropriate }\end{array}$ & $\begin{array}{l}\text { (Omitted from Q1 for brevity after pilot } \\
\text { testing; write-in option under Q2) }\end{array}$ \\
\hline $\begin{array}{l}\text { 6.6. By 2020, protect and restore water-related } \\
\text { ecosystems, including mountains, forests, wetlands, } \\
\text { rivers, aquifers and lakes }\end{array}$ & $\begin{array}{l}\text { (Omitted from Q1 for brevity after pilot } \\
\text { testing; write-in option under Q2) }\end{array}$ \\
\hline $\begin{array}{l}\text { 6.A. By 2030, expand international cooperation and } \\
\text { capacity-building support to developing countries in }\end{array}$ & F) Building national capacity \\
$\begin{array}{l}\text { water- and sanitation-related activities and } \\
\text { programmes, including water harvesting, } \\
\text { desalination, water efficiency, wastewater treatment, } \\
\text { recycling and reuse technologies }\end{array}$ & \\
\hline $\begin{array}{l}\text { 6.B. Support and strengthen the participation of local } \\
\text { communities in improving water and sanitation }\end{array}$ & $\begin{array}{l}\text { G) Strengthening local community } \\
\text { management }\end{array}$ \\
\hline
\end{tabular}

An informal survey work group within the R\&L constituency and a survey expert from the Odum Institute for Social Science Research at UNC reviewed questions targeting country representatives for content, length, language, and clarity. They were then uploaded to the Qualtrics software platform and pilot-tested by the R\&L work group (alpha testers) and external reviewers (beta testers), including international students and an information technology specialist. Reviewer feedback, especially to reduce length, was incorporated into the questionnaire design.

Following review of preliminary findings from the country constituency questionnaire, two modified versions were developed for the R\&L constituency and 'all other' constituencies. This generally involved minor language adaptation (e.g. 'decisions' versus 'research' versus 'activities'), to maintain comparability among versions. Although the country questionnaire was originally designed to avoid future projection, one question on future research priorities was added to the $R \& L$ and 'all other' versions, for the sake of comparison. In addition, funding and stakeholder interaction questions were added to explore potential drivers behind interconstituency differences.

The final surveys consisted of 20-24 questions each. The country and 'all other' constituency questionnaires and recruitment messages were translated from English into French and Spanish to cover the three working languages of SWA, while the R\&L survey and recruitment messages were offered in English only, at the work group's request. Full-text English-version

This article is protected by copyright. All rights reserved. 
questionnaires are provided as supplementary information. Recruitment email text and questionnaires were reviewed by the UNC Office of Human Research Ethics (IRB \#15-5808, exempt).

\section{Survey Deployment}

A printed pre-survey announcement was made available at the 15-17 March 2016 SWA Sector Ministers' meeting in Addis Ababa, to engage respondents from the country constituency. The country questionnaire was deployed in May 2016, followed by preliminary data analysis, review of initial findings, and revision and translation of the remaining questionnaire and recruitment text. The R\&L and 'all other' constituency questionnaires were then co-deployed from late September to early October 2016. Invitations shared a common anonymous link with all SWA representatives from each constituency, and invitees self-selected to participate. Following the two-week deployment, interpersonal recruitment led to one additional survey response, submitted three days after the deadline.

\section{Data Cleaning and Analysis}

Partial responses with answers to at least three questions (about 15\% of the questionnaire) were included in the dataset, while those with fewer answers were excluded. Questions left blank were excluded from analysis, as was one duplicate response from the same respondent. All responses were de-identified, and respondents remained anonymous aside from automated IP address and geolocation collection by Qualtrics. Responses in French were translated to English; no responses were received in Spanish.

Data from related questions were matched across the three questionnaires, and analysed by question and constituency grouping. Data interpretation methods aimed to value quantitative and qualitative data as equivalent forms of insight. Quantitative (multiple-choice) responses were tallied and graphed using Microsoft Excel. Qualitative (open-ended) question responses were coded using line-by-line 'in vivo' codes (as close as possible to actual wording used by respondents), and tallied by constituency and frequency to identify trends. To achieve this, conventional qualitative content analysis and description (Hsieh \& Shannon, 2005; Kim, Sefcik, \& Bradway, 2017) were combined with some elements of grounded theory (Charmaz, 1996). A

This article is protected by copyright. All rights reserved. 
standard codebook was not developed; rather, each set of question responses was assessed inductively and not constrained to fit prior question responses. A single rater performed the qualitative data analysis with limited spot-checking by another member of the research team.

Although sections and questions differed slightly on each of the three questionnaires, responses to related questions were grouped into four primary categories: respondent characteristics, research priorities, learning and training, and funding and stakeholder interactions. Questions were assessed individually, and question-specific results were then summarized across these categories to interpret themes.

To develop a weighted sum for the research prioritization, values for each question 1 category (very confident $=3$, somewhat confident $=2$, not confident $=1$, unsure $=0$ ) were assigned and multiplied by the number of respondents selecting that category. To account for novel writtenin categories from question 2 and achieve comparability of scales, target areas named as a 'knowledge gap or area of concern' were considered equivalent to 'not confident' and set to 1 , while target areas that went unnamed were considered to correspond to moderate or greater confidence and set to 2.5. Although the calculation methods for questions 1 and 2 differed, the categories were integrated in one rank order based on their respective weighted sums. A scaled average score divided the weighted sums by the number of effective respondents.

This article is protected by copyright. All rights reserved. 


\section{Results}

Although overall confidence about knowledge and ability to work toward Goal 6 was high, with $86 \%$ of responses falling into the 'very confident' or 'somewhat confident' categories, only $7 \%$ of respondents were 'very confident' across all Goal 6 target areas included in question 1. Target 6.3, halving the proportion of untreated wastewater, was consistently named over multiple questions as an area of low confidence. Further, respondents extensively cited funding and financing as strong determinants of WaSH-related research and programming activities. Some perceptions (e.g. agreement across information sources) differed among constituencies, and cross-sector communications appeared somewhat challenged when it came to learning opportunities and research engagement.

\section{Representativeness}

Response rates were reasonable for an anonymous web-delivered survey, averaging $10 \%$ of those on the SWA mailing lists (about 759 individuals; Table 3). Actual response rates were probably higher because some email addresses may have been duplicates, no longer active, or for non-WaSH professionals (e.g. caterers). In total, 76 individuals responded (30 from the country constituency, six from the R\&L constituency, and 40 from all other constituencies).

Table 3. Response rates for three questionnaire deployments (country, R\&L, and 'all other')

\begin{tabular}{|c|c|c|c|c|c|}
\hline Constituency & Responses & $\begin{array}{l}\text { Partner } \\
\text { Orgs. }^{2}\end{array}$ & $\begin{array}{l}\text { Ratio } \\
\text { (per } \\
\text { org.) }\end{array}$ & $\begin{array}{c}\text { Email } \\
\text { Addresses }\end{array}$ & $\begin{array}{c}\text { \% Responders } \\
\text { (per email) }\end{array}$ \\
\hline Country & 30 & 53 & 0.57 & 227 & $13.2 \%$ \\
\hline Research \& Learning & 6 & 18 & 0.33 & 41 & $14.6 \%$ \\
\hline All Other & 40 & 80 & 0.50 & 491 & $8.1 \%$ \\
\hline $\begin{array}{r}\text { External Support }{ }^{1} \\
\text { (includes multilateral } \\
\text { organizations) }\end{array}$ & 16 & 22 & 0.73 & 135 & $11.9 \%$ \\
\hline $\begin{array}{r}\text { Civil Society }^{1} \\
\text { (national, } \\
\text { international or } \\
\text { regional levels) }\end{array}$ & 22 & 52 & 0.42 & 319 & $6.9 \%$ \\
\hline Private Sector ${ }^{1}$ & 2 & 6 & 0.33 & 37 & $5.4 \%$ \\
\hline Total & 76 & 151 & 0.50 & 759 & $10.0 \%$ \\
\hline
\end{tabular}

This article is protected by copyright. All rights reserved. 
${ }^{1}$ Numbers not in bold are extrapolated, as only $75 \%$ of other respondents reported their constituency affiliation.

${ }^{2}$ Estimated as of November 2016. New partners are added on an ongoing basis.

Survey respondents were working in an estimated 36 countries across all five UN world regions (excluding the sub-region of Latin America and the Caribbean). Approximately half (47\%) of all responses and close to two-thirds of the country responses came from sub-Saharan Africa, mirroring the 2016 membership of SWA. Responses also came from Asia and the Middle East (21\%), Europe (17\%), North America (12\%), and Oceania (3\%). Some degree of misclassification via automated geolocation was likely, as contact information was not required of respondents, and two responses appeared to come from a work travel location. Respondents reported having diverse educational backgrounds and professional roles. Almost half had studied engineering or natural sciences, while other common fields included business, economics, medicine, public health, sociology, and political science.

This sample represented at most half of all SWA partner organizations (Table 3). Respondents were not limited to one person per agency; therefore, the actual ratio probably was lower. Geolocations suggested that at most up to six people from the same country responded to any given questionnaire. Because the 'all other' survey went to multiple constituencies and only $75 \%$ marked their constituency affiliation, the breakdown for this survey was extrapolated from those who did respond (Table 3). The smallest constituencies, $R \& L$ and private sector, had the lowest estimated rates of response per member organization (one in three). The 'all other' survey had the lowest rate of response per email address. Eighty per cent of the surveys included in the study were complete, while $20 \%$ were partial responses. The sample was deemed satisfactory for the study purposes; however, differences in constituency size and demographic question response rates primarily recommended stratification of the data into the three questionnaire groupings (countries, R\&L, and others), rather than by educational background or current professional responsibilities.

\section{Research Priorities}

Overall confidence was high, but not equivalent across all target areas. Ninety-three per cent of respondents were less than 'very confident' about their knowledge/ability to work in at least one of the Goal 6 target areas (question 1), and $43 \%$ reported a specific area of concern or knowledge gap related to Goal 6 (question 2). We ranked the need for research under each

This article is protected by copyright. All rights reserved. 
target area using a weighted sum, where the lowest values corresponded to the least confidence (Table 4). Uncertainty regarding managing untreated wastewater or faecal sludge was common. For example, one country respondent wrote, 'I have specific knowledge gaps in the management of untreated wastewater... especially within the context of [country] where we don't have treatment works. Wastewater is indiscriminately disposed of in settlements, open fields, and waterways'. Some top written-in concerns from question 2, such as managing wastewater and sludge and capacity building, reinforced the multiple-choice categories and were not double-counted. Others (namely financing and sustainability) represented novel categories and were added to the ranking (Table 4). Written-in responses cited fewer than three times, such as interdependency with other SDGs, were not elevated as priorities (Table 4).

Table 4. Weighted ranking of confidence around Goal 6 targets from question $1(n=76)$, including two of the top written-in concerns from question 2 ( $n=33$, referenced as 'added by respondents'). The lowest weighted sum corresponds to the least confidence.

\begin{tabular}{|r|c|c|l|l|}
\hline $\begin{array}{r}\text { Weighted } \\
\text { Sum }^{\mathbf{1}}\end{array}$ & $\begin{array}{r}\text { Average } \\
\text { Score }^{2}\end{array}$ & Rank & Response Category & Goal 6 Reference \\
\hline $\mathbf{1 3 5}$ & 1.85 & 1 & $\begin{array}{l}\text { Managing untreated } \\
\text { wastewater/faecal sludge }\end{array}$ & Target 6.3 \\
\hline $\mathbf{1 6 9}$ & 2.25 & 2 & Ending open defecation & Target 6.2 \\
\hline $\mathbf{1 7 2}$ & 2.29 & 3 & $\begin{array}{l}\text { Addressing inequalities } \\
\text { among sub-populations }\end{array}$ & $\begin{array}{l}\text { Targets 6.1 and 6.2 } \\
\text { "equitable" }\end{array}$ \\
\hline $\mathbf{1 7 3}$ & 2.34 & 4 & Achieving universal access & $\begin{array}{l}\text { Targets 6.1 and 6.2 'for all' } \\
\text { 'universal' }\end{array}$ \\
\hline $\mathbf{1 7 4}$ & 2.38 & 5 & Building national capacity & Target 6.A \\
\hline $\mathbf{1 8 2 . 5}$ & 2.40 & 6 & Financing & (added by respondents) \\
\hline $\mathbf{1 8 3}$ & 2.47 & 7 & Improving levels of service & $\begin{array}{l}\text { Targets 6.1 and 6.2 'safe' } \\
\text { 'adequate' }\end{array}$ \\
\hline $\mathbf{1 8 5 . 5}$ & 2.44 & 8 & $\begin{array}{l}\text { Ecosystem } \\
\text { sustainability/resource } \\
\text { conservation }\end{array}$ & $\begin{array}{l}\text { Targets 6.4, 6.5, and 6.6 } \\
\text { (added by respondents) }\end{array}$ \\
\hline $\mathbf{1 8 6}$ & 2.51 & 9 & $\begin{array}{l}\text { Strengthening local } \\
\text { community participation }\end{array}$ & Target 6.B \\
\hline
\end{tabular}

${ }^{1}$ Although the nature of the data did not recommend assessing statistical differences, the greatest separation appeared between ranks one and two. The range of possible weighted sums using these methods was 76-228 for question 1 categories, or 76-190 for question 2 categories.

2Estimate of 'average' answer given the actual (for question 1 categories) or potential (for question 2 categories) number of respondents where very confident $=3$, somewhat confident $=2$, not confident $=1$, and unsure responses were excluded. The computational

This article is protected by copyright. All rights reserved. 
method differs for target areas written-in by respondents, where topics named as a 'knowledge gap or area of concern' were considered equivalent to 'not confident' and set to 1 , and unnamed topics were assigned an intermediate confidence value of 2.5 given no further information.

${ }^{3}$ The topic of ecosystem sustainability was dropped from question 1 for brevity following pilot tests of the survey, although it appears in the Goal 6 targets (Table 2). Written-in responses from question 2 elevated its importance and provided a basis for calculating the weighted sum.

Sub-categories were matched to each target area (Figure 1), drawing from prominent information needs reported on questions 3, 4, and 5 (where more information would have aided the respondents' work or decisions over the past six months). These included strategic planning and prioritization, sector coordination and collaboration, monitoring and evaluation, affordability (e.g. subsidies, tariffs), reaching poorest populations, and appropriate technologies. Additional sub-categories came from prominently reported recent or prospective work areas described under questions 6 (topics of recent research or decisions) and 7 (pressing future needs; R\&L and 'all other' questionnaires only). These included equality and non-discrimination; WaSH in institutions and public spaces; WaSH finance or business models; resilience, security, and climate change; ecologically sustainable solutions; and universal access including remote areas.

This article is protected by copyright. All rights reserved. 
-Strategic planning/prioritization

- Monitoring and evaluation

-Affordability (e.g., subsidies, tariffs)

-Appropriate technologies

- Sustainable/ecological solutions

- Resilience/security/climate change

\section{Ending open defaecation}

-Appropriate technologies

-Monitoring and evaluation

\section{Addressing inequalities among sub-populations}

-Gender equality/non-discrimination

-Equality/non-discrimination

-Monitoring and evaluation

\section{Achieving universal access}

- Sector coordination/collaboration

-WaSH in institutions and public spaces

- Universal access/remote areas

Building national capacity

- Sector coordination/collaboration

-National policy/strategy/human rights law

Financing

-Equality/non-discrimination

-Resilience/security/climate change

Improving levels of service

-Water quality/safety

-Equality/non-discrimination

-Monitoring and evaluation

Ecosystem sustainability/resource conservation

-Strategic planning/prioritization

-Sustainable/ecological solutions

Strengthening local community participation

-Equality/non-discrimination

- Reaching poorest populations

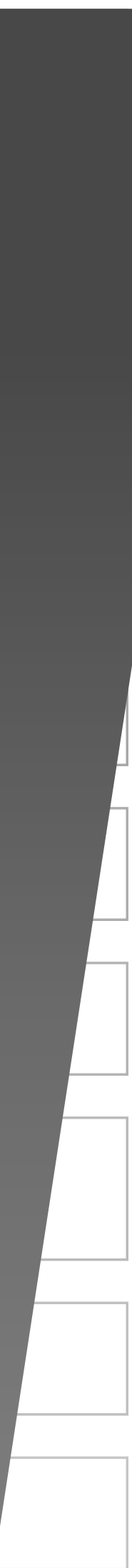

This article is protected by copyright. All rights reserved. 
Figure 1. Hierarchical outline of proposed WaSH research agenda under Goal 6 (full text research agenda offered as supplementary information)

The full resulting research agenda is provided as supplementary information. Research questions were drafted under each sub-category, using direct qualitative description from questions 6 and 7 if available. Rank ordering corresponds to the quantitative frequency of responses to questions 1-5. In the ranked outline structure of the research agenda (Figure 1), we sought to balance inclusivity with brevity, based on separation in the frequency of responses. Thus, more sub-categories were included under the highest priority target area (managing untreated wastewater or faecal sludge). Sub-categories selected by a minority of respondents or unrelated to the main Goal 6 target areas were excluded.

Priorities were pooled equally among the 76 survey respondents to develop the research agenda, and responses generally agreed among constituencies. Statistical comparison was not feasible due to differences in sample size, but some priority knowledge areas clearly differed among respondents from different constituencies. When comparing the three sub-groupings, the $R \& L$ constituency had the least confidence about ending open defaecation (fully half were not confident), while the country constituency had the least confidence about managing untreated wastewater (only $14 \%$ were very confident) and the other constituencies had the least confidence about building national capacity (just 38\% were very confident). Write-in recommendations for financing and ecosystem sustainability came mainly from the non-R\&L constituencies. The country and 'all other' constituencies often mentioned WaSH finance or business models, as well as costing, budgeting, and donor management, while the R\&L group did not broach this topic. One respondent described the intensity of financial limitations, writing '....with the growing economic crisis, it will be difficult to talk about universal access.... Only the 'all other' constituencies, which included CSOs, raised menstrual hygiene management and gender equality (frequency $=5$ ).

When comparing questions about recent and future challenges (questions 6 and 7), the R\&L and 'all other' constituencies viewed climate change and resilience, equity and inclusion, and WaSH in institutions and public spaces as more pressing under a future scenario. Sludge management and WaSH law or policy were instead perceived as more pressing in recent experience, including the country constituency (question 6), which may have been an effect of the recent adoption of

This article is protected by copyright. All rights reserved. 
Goal 6. Education and knowledge sharing, and utility management and service delivery, were more commonly reported as critical to future success, excluding the country constituency. For example, one respondent from a CSO wrote, '[half] of [the people in my country] do not know about this $\mathrm{WaSH} . .$. we are [in the] process to educate our people'.

\section{Learning and Training}

Country respondents relied mainly on easy-to-access informational resources such as the internet or personal contacts to address WaSH questions, with secondary use of more distant resources such as contacts within a professional network. Country respondents viewed multilateral information sources (frequency $=43$ ) and national information sources (frequency $=$ 29) as the most 'useful' (defined as accessible, understandable, relevant, and/or sufficient) for addressing WaSH questions. Universities (frequency $=11$ ) and news outlets (frequency $=2$ ) were considered useful information sources less often. Respondents regarded partnership networks (frequency $=31$ ), communications departments (frequency $=24$ ), and stakeholders (frequency = 20 ) as the most important information disseminators. Stakeholders could include any party with an interest or concern in the work, whether or not they participate.

Synthesizing evidence and applying it remain important hurdles in practice. About $13 \%$ of respondents had no difficulty obtaining WaSH information, while the rest reported one or more barrier to seeking information and using it to inform decisions (Figure 2). Information was often perceived as conflicting, unreliable, inaccessible, or outdated, especially among the 'countries' and 'all other' constituencies. This suggests differences in perceptions, approaches, and/or levels of practice at identifying and consolidating reliable information. Interestingly, lengthy or technical information was a less frequent cause of complaint than information that was too brief or general (Figure 2). Still, reference to one's particular country or situation, expert analysis or critique, and executive summaries or synopses were highly valued communication mechanisms, suggesting that both brief and technical information play a role in knowledge uptake.

This article is protected by copyright. All rights reserved. 


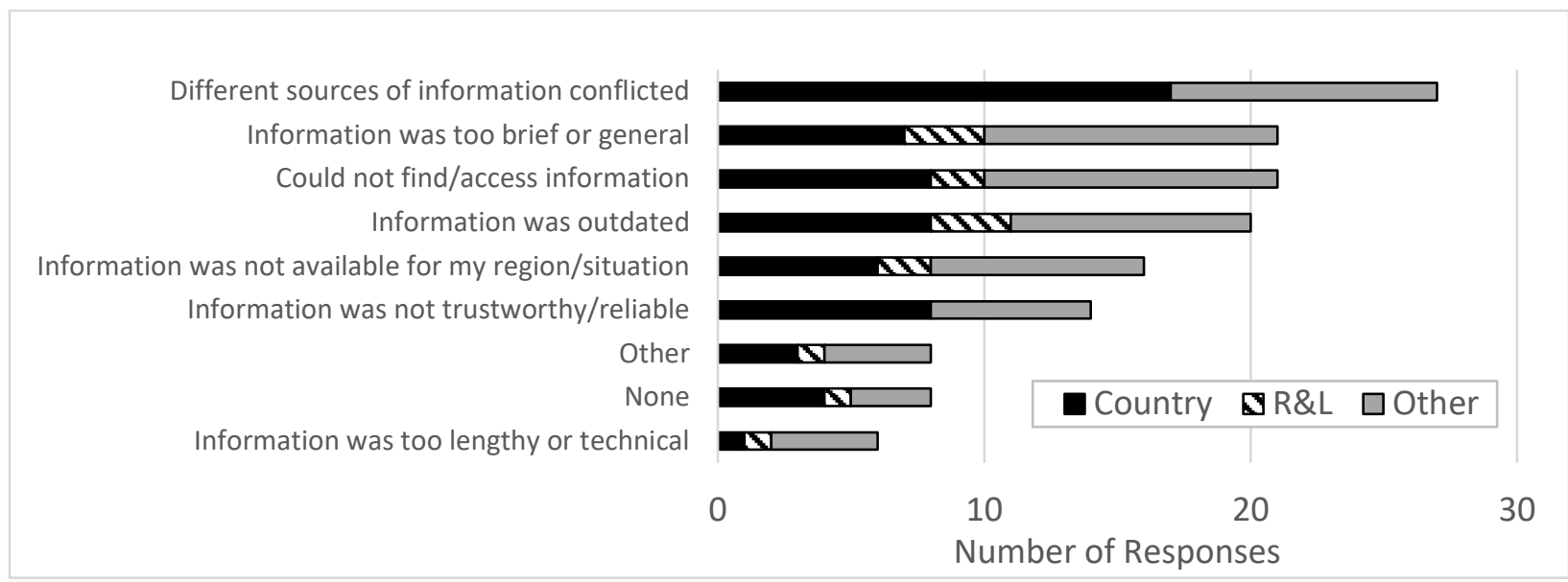

Figure 2. Challenges reported in seeking WaSH information by constituency, permitting more than one response category $(n=62)$

Constituencies differed regarding learning needs and access to training, wherein $20 \%$ reported no challenges (Figure 3). In addition to more or broader funding opportunities, respondents from the country and 'all other' constituencies desired additional learning and training opportunities (e.g. discussion fora, training manuals, and courses; frequency $=9$ ). These constituencies concurrently perceived barriers to participating, such as excessive cost or not receiving a notice or invitation (Figure 3). Information synthesis was highly valued within the country constituency; in particular, in-person seminars or lectures were deemed useful by $87 \%$ of respondents. The R\&L constituency members instead appeared more saturated with learning and training opportunities, where two-thirds were primarily limited by a lack of time (Figure 3 ).

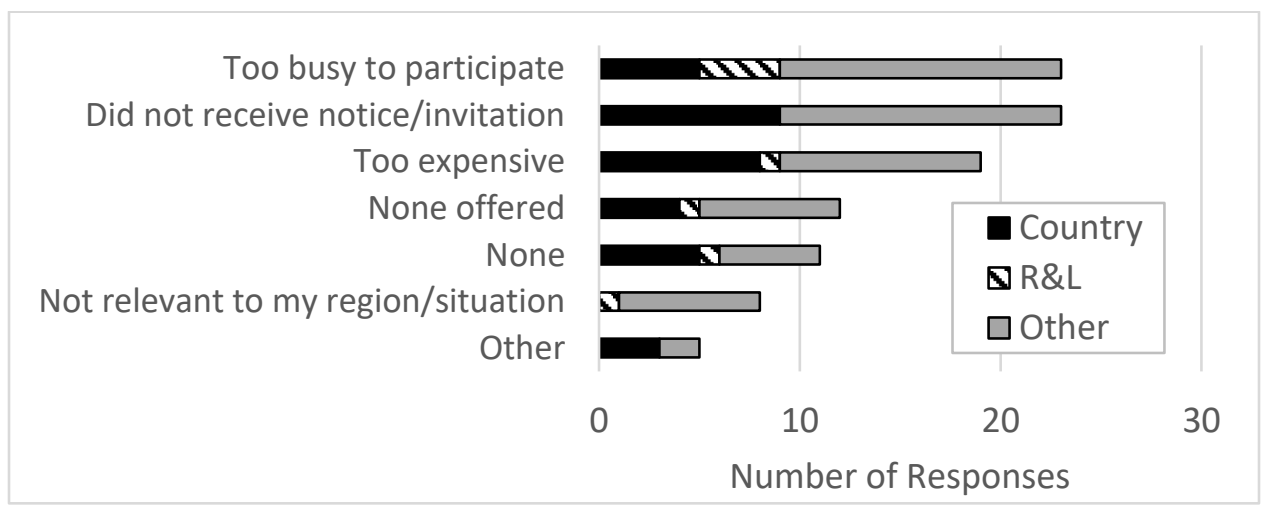

Figure 3. Barriers to seeking WaSH education or training opportunities by constituency, permitting more than one response category $(n=57)$

This article is protected by copyright. All rights reserved. 


\section{Funding and Stakeholder Dynamics}

Funding and stakeholder relationships revealed accountability imbalances among constituencies. WaSH requests for proposals often had narrow topic specificity (Figure 4), while the R\&L and other constituencies perceived lack of funding for undertaking desired WaSH work or activities (Figure 5). When combined with country constituency results $(n=64)$, top-ranked non-informational barriers to undertaking WaSH activities included: (1) lack of financial resources or funding, (2) lack of technical or human resources, and/or (3) lack of political traction to pursue alternatives. Narrow requests for proposals likely increase research relevance to the funder, and may take into account (either informally or formally) the interests of the broader WaSH professional community.

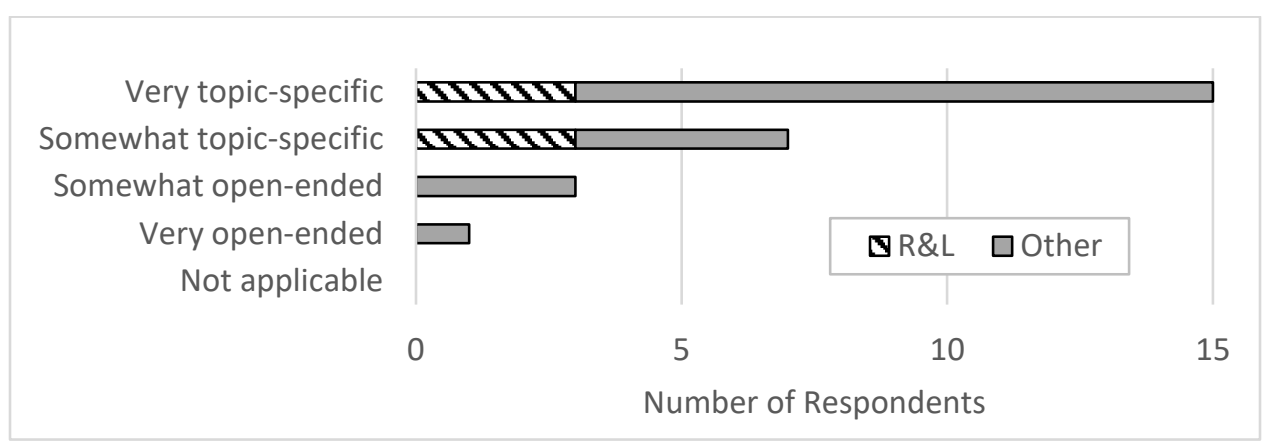

Figure 4. Perceptions by constituency of the degree of topic specificity among WaSH requests for proposals $(n=26)$

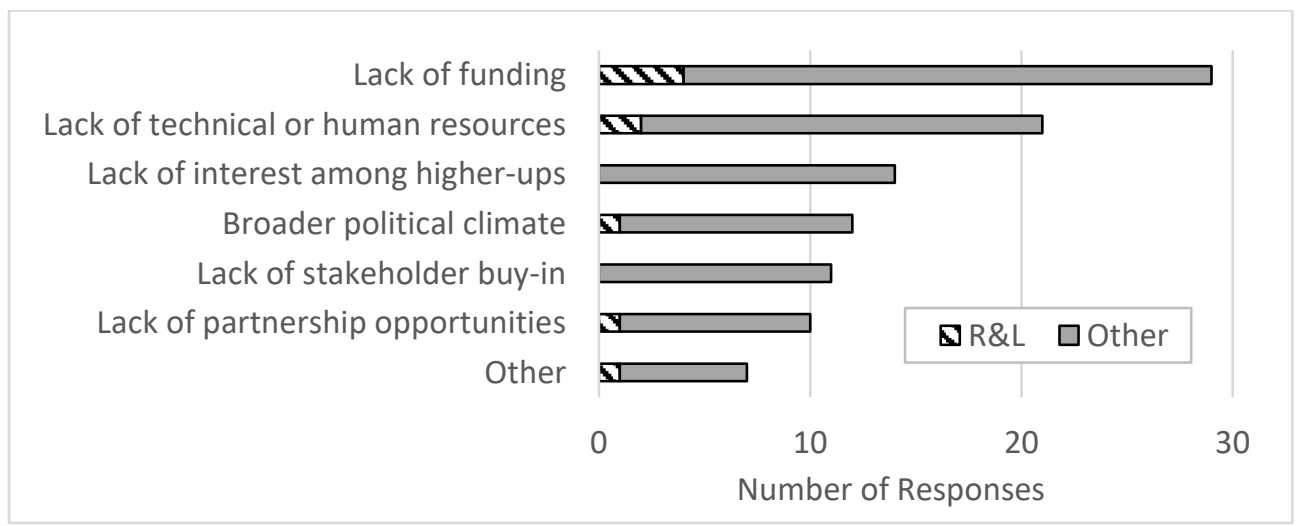

This article is protected by copyright. All rights reserved. 
Figure 5. Obstacles to undertaking WaSH research or activities by constituency, permitting more than one response category $(n=37)$

Partnerships and stakeholder involvement were important to receiving funding (Figure 6). Still, stakeholders (a term broadly inclusive of end users, sponsors, and any affected parties) were not always included in research or other activities, especially at project start-up when the resources, scope, and methods are typically defined (Table 5). These varied roles and interorganizational dynamics may inadvertently exclude WaSH stakeholders, such as in-country end users, who do not fund or review proposals. One respondent from a CSO cited absent or weak downward accountability and 'unhealthy competition for resources and visibility' as challenges in the SDG era. Twelve respondents offered suggestions to help better match WaSH funding to the needs of end users, citing capacity building, opportunities for reflection, funding availability, and partnerships, while two did not perceive any dysfunction in these dynamics.

Lack of scientific rigor or pre-proposal planning Lack of plans for partnership/stakeholder involvement Broader political climate

Other

Lack of knowledge/trust in applicant's organization Doesn't match organizational directions Doesn't match interests of donors/constituents

0

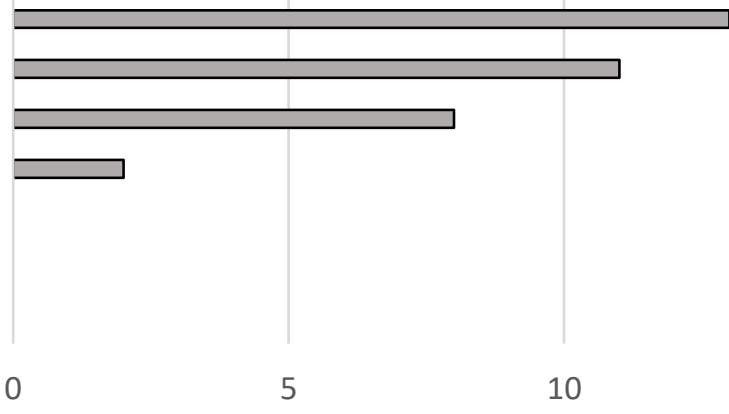

Number of Responses

Figure 6. Reasons reported by respondents from funding organizations ('all other' constituencies) for declining to fund WaSH research or activities, permitting more than one response category $(n=20)$

Table 5. Reported stages at which stakeholders are involved in WaSH research or activities, permitting more than one response category $(n=36, R \& L$ and other)

\begin{tabular}{|c|c|}
\hline Stage of Work & $\begin{array}{c}\text { \% Reporting } \\
\text { Stakeholder Involvement }\end{array}$ \\
\hline Scoping & $50 \%$ \\
\hline
\end{tabular}

This article is protected by copyright. All rights reserved. 


\begin{tabular}{|c|c|}
\hline Design & $67 \%$ \\
\hline Implementation & $81 \%$ \\
\hline Analysis/Interpretation & $53 \%$ \\
\hline Dissemination & $72 \%$ \\
\hline
\end{tabular}

\section{Discussion}

The research agenda (Figure 1; supplementary information) lists areas of priority, including categorization and relative ranking within the overarching ambition of clean water and sanitation. Importantly, some Goal 6 target areas correspond to weak confidence among surveyed WaSH professionals, suggesting a need for renewed attention to knowledge development and sharing. Managing untreated wastewater and sludge engendered the least confidence, and could be a focal area for R\&L efforts. Underlying synergies, such as support for improved financing and equity, would support achievement of multiple targets. A literature review by Hutton and Chase (2016) matched many of the priorities found in this study, recommending increased focus on equity, financing strategies, social welfare consequences of poor WaSH services (especially regarding gender), synergies between WaSH and nutrition, sustainable behaviour change, slum environments, and poverty reduction. In contrast, it presented a more optimistic view toward potential options for untreated wastewater and faecal sludge management.

Economics and finance information needs figured prominently among research priorities, but were not reflected by respondents from, nor potentially membership in, the R\&L constituency. A synthesis report backs the perception that current financial resources are inadequate to achieve Goal 6, and recommends increasing efficiency of existing financial resources while mobilizing additional and innovative forms of domestic and international finance (UN Water, 2018). A critical analysis by Bartram, Brocklehurst, Bradley, Muller, and Evans (2018) similarly identified a lack of reference to financing needs in the Means of Implementation (Mol) for Goal 6. Our findings suggest development of a research agenda by researchers alone may not meet needs across all constituencies, and multidisciplinary, multi-stakeholder approaches are desirable to capture holistic requirements (Bryant et al., 2014).

Notably, slightly different pictures were seen when inferring priorities from respondents' actual recent needs versus broad future projection, which requires greater cognitive processing.

This article is protected by copyright. All rights reserved. 
Adding a question on future research priorities to the $R \& L$ and 'all other' versions offered a hypothetical comparison between different potential methods of research agenda construction. Relying solely on the researchers' and other constituencies' future priorities submitted via an open question (question 7) would have downplayed the need for evidence on faecal sludge management and open defaecation identified using a structured questionnaire; these topics were mentioned at frequencies of $4 \%$ and $2 \%$, respectively. Retrospective question 6 , in contrast, showed these were clear areas of concern for national WaSH professionals and others. This example illustrates the subtle differences in forward versus backward planning processes, as well as the benefits of considering diverse perspectives.

Learning and training findings suggested research translation is not a singular bottleneck, as information generation, information synthesis, and communication were all perceived as important needs for achieving Goal 6 targets. The review by Hutton and Chase (2016) called for additional evidence to support Goal 6 implementation, as well as evidence synthesis to support decision-making within specific contexts (e.g. at country or regional level within rural or urban areas). In addition to evidence about efficacy and effectiveness of proposed WaSH solutions (whether something could work at scale), local context (broadly inclusive of the enabling environment, people, and institutions) is an important influence on the eventual outcomes of public health interventions (May, Johnson, \& Finch, 2016; Pfadenhauer et al., 2017). For example, science-policy-practice gaps may stem from misalignment of institutions, incentives, and resources (Ménard, Jimenez, \& Tropp, 2018). In the spirit of quality improvement, improved coordination among actors often requires interactive and iterative problem solving at multiple time points, rather than a single push.

This finding generally agrees with existing literature. Simplistic linear models assuming research will be taken up and used by policy-makers and practitioners within a few years of its publication have been supplanted with a more complex and nuanced understanding (Cairney, 2016; De Goede, van Bon-Martens, Mathijssen, Putters, \& Van Oers, 2012; Georgalakis, 2016; Nutley et al., 2007). Such models include multi-way communication, knowledge translation, and mediation, which are best achieved via regular, structured, interpersonal interaction (Cash et al., 2003; Gupta, 2014). Reflecting increased complexity in development goals, water governance

This article is protected by copyright. All rights reserved. 
models must embrace inclusive knowledge sharing, decision-making processes, coordination, and negotiated outcomes (Tropp, 2007).

The mode and source of information also mattered to respondents. Both brief and lengthy formats were considered useful, as were perceived trustworthiness and accessibility of the information source. For example, the peer-reviewed scientific journal publications preferred by academics may effectively reach only fellow researchers, in part due the monetary barriers of paid subscription or fee-based open access models (Tennant et al., 2016). Intermediary knowledge brokers can serve to translate, synthesize, and communicate findings across sectors (Cash et al., 2003). These 'boundary' organizations or individuals at the science-policy-practice interface may include multilaterals and funding agencies, who vet the rigour of proposed research (Figure 6) and help to disseminate it.

Distinct from information-related challenges, because availability of financial resources was a primary limiter across all constituencies when making decisions about whether to undertake WaSH activities, some respondents recommended detailing information on costs and potential financing avenues alongside WaSH recommendations. Similarly, a 2013 focus group discussion with SWA finance ministers about WaSH decision-making recommended ongoing, multiministry, multi-stakeholder dialogue, as well as modular briefing materials that make a strong case for WaSH as a sound investment and contributor to economic growth (Brocklehurst, 2013). These findings led to development of a WaSH Policy Research Digest brief and webinar series coordinated by the UNC Water Institute.

This research priority-setting and learning challenges survey is one of several efforts to accelerate collective progress toward WaSH development goals. A broad consultative exercise cross-cutting all SDGs produced one research question directly relevant to WaSH: 'What evidence is there that private sector finance has played a major role in the provision of basic services such as access to water, sanitation or energy, for the poorest quintile in lower-income countries?' (Oldekop et al., 2016). Specific to water and health, a research prioritization

This article is protected by copyright. All rights reserved. 
workshop involving students, academics, and practitioners was also held at the 10th International Water \& Health Seminar in Cannes, France in June 2018.

The GLAAS process gathers and compares national-level WaSH data to help countries identify priorities and barriers to service provision, helping to promote a culture of accountability, partnership, and shared responsibility (UN Water \& World Health Organization, 2017). One key GLAAS finding in 2017 was that while national WaSH budgets are increasing, they are not on par with global aspirations. A secondary review of GLAAS survey data found accountability was more developed for water versus sanitation services, with little data provided on wastewater and faecal sludge management (Jiménez, Livsey, Åhlén, Scharp, \& Takane, 2018). To improve accountability, it recommended improved access to information, participatory policies, and increased regulatory capacity, as well as modification of the survey to better capture accountability mechanisms.

Other efforts addressing the use of evidence in decision making include the WASH PaLS programme of the United States Agency for International Development (USAID), funded in 2016 to enhance global learning and adoption of the evidence-based programmatic foundations needed to achieve the SDGs. The TRAction project (Translating Research into Action), also funded by USAID and launched in 2014, recently conducted a survey on Incentives for Engagement in Implementation Research and Delivery Science (IRDS). Australia's Civil Society Water, Sanitation and Hygiene Fund placed substantial emphasis on global WaSH knowledge and learning from 2013-2018, funding research grants related to programming, webinars, and learning events.

Based on the observed differences among constituencies, we recommend evidence-based mechanisms for determining and vetting research priorities to enhance cost-effectiveness and speed progress toward global development goals. In agreement with this study, others recommend information collection and decision models as a starting point for research agenda construction (Bryant et al., 2014; Doyle, 2005; Elder, Bengtsson, \& Akenji, 2016). A common aspect of these designs involves transparently attracting and capturing the viewpoints of diverse stakeholders. For example, the European Commission has been promoting 'responsible research and innovation' since 2014 to ensure societal actors (e.g. researchers, citizens, policymakers,

This article is protected by copyright. All rights reserved. 
businesses) work together throughout the research process, helping to align processes and outcomes with the values, needs, and expectations of society (European Commission, 2018).

\section{Limitations}

Respondents self-selected from SWA's partnership network, and their views may not represent all SWA members or WaSH professionals worldwide. Low quality or intermittent internet access may have excluded some respondents. Differences among constituencies may have stemmed from the within-constituency sample (e.g. if co-workers from the same unit took the survey) or legitimate differences in topic representation based on limited constituency membership. Survey responses may have been affected by social desirability bias; for example, the rating for partnership networks as a communication outlet could have been affected by perceived expectations of SWA members. This was likely reduced by the anonymous nature of the survey; however, reporting bias was not explored via data triangulation, participant observation, or other means. Follow-up in-depth interviews or focus group discussions using the developed interview guide are recommended to improve the depth of responses and clarify some questions raised by this survey, and could help to target missing perspectives (e.g. from newer SWA partners in Latin America and the Caribbean).

Assessment of the psychometric properties of the questionnaire instrument, such as validity, would require test-retest replication under different scenarios (Lewis et al., 2015). In addition, review of the full results by a second rater would have been beneficial, enabling assessment of inter-rater reliability. Sample size differences and the categorical nature of the data limited quantitative observations (e.g. tests of statistical significance). The basis for research prioritization likewise merged two different rating schemes, which limited its utility for relative comparison; however, pilot testers felt the survey design was too long when all possible options were included under the multiple-choice segment. When interpreting the results, greater emphasis should be placed on presence of the research agenda themes than their specific ordering.

A small degree of misclassification was possible, as some respondents (about 5\%) reported current professional affiliations that did not match their expected constituency. This was most prevalent for the country constituency and may have reflected recent job changes. Few government ministers or advisors within the country constituency responded, representing

This article is protected by copyright. All rights reserved. 
perhaps $20 \%$ of country respondents, although high-level managerial and technical personnel were well represented, especially from ministries of water. Two of six respondents from the R\&L constituency participated in survey development, but this posed a minimal concern based on the length of time between survey development and deployment.

\section{Recommendations}

In general, this study inductively explored research and learning needs rather than testing a preexisting hypothesis, so the findings serve as a starting point for troubleshooting and future improvement. While SWA has defined 'building blocks' and 'collaborative behaviours' (SWA, 2018), partners could further develop guidance and model good practices for promoting efficient exchange at the WaSH science-policy-practice interface. A need for mindful external accountability applies to all sectors. Some R\&L organizations may be especially vulnerable to weak downward accountability, since publishing scientific literature and obtaining research funding are the primary drivers of academic career development. Commitments to support learning and progressive actions of others may have fewer or more indirect rewards, and publishers may not as readily accept applied research.

Findings point to some areas where partnership networks, including SWA, could assist in coalescing efforts among WaSH researchers, knowledge brokers, decision makers, practitioners, and others. These include:

- Fostering an enabling environment in which WaSH professionals have portals of access to a variety of established reference material and layers of interpersonal support;

- Opening up and promoting interactive seminars or webinars (e.g. offered by R\&L institutions or networks such as SuSanA, the Rural Water Supply Network, and the UNC Water Institute) to offer up-to-date expert interpretation and information synthesis to peer scientists, practitioners, and stakeholders, potentially with messages tailored to different audiences;

- Helping WaSH professionals to connect more easily with others in their extended professional network, for example via personal referral or access to specific listservs of experts, especially when issues or questions cannot be immediately addressed by more proximate resources, or when preparing project proposals that require partnerships;

This article is protected by copyright. All rights reserved. 
- Developing or recommending accountability mechanisms (e.g. grant criteria requesting evidence of past stakeholder satisfaction) that tie project follow-up, downward accountability, and applied (demand-driven) research to enhanced opportunities for future funding and publication;

- Promoting stakeholder involvement (or conscientious exclusion if warranted) in a consistent manner throughout all WaSH research or implementation projects and stages (e.g. via guidance on best practices);

- Facilitating communication and dissemination pathways for individual research or educational activities, especially from R\&L institutions in the global South; and

- Assisting the country constituency, in particular, with increased opportunity for interpersonal interaction among their peers, especially to debrief and discuss how to implement new information or guidance.

$R \& L$ actions in progress include additional recruiting (especially of $R \& L$ institutions in the global South), establishing country-level focal points to improve within-country research engagement, and garnering additional external facilitation support as well as representation on the SWA steering committee. Such facilitation can stimulate active rather than passive networking. At a local level, researchers are likely able to individually discern whether answers to a given question are (1) currently missing but feasible to obtain, (2) available but lacking synthesis or communication, or (3) intractable. For example, R\&L members could ground-truth the research agenda in their respective locations to construct dialogue about what evidence may or may not be needed in a given country or regional context (Wickremasinghe et al., 2016). A secondary exercise at a global level to map evidence gaps within the WaSH literature (e.g. Rehfuess et al., 2016) and compare these to the suggested research agenda could help to identify which of these categories apply to each priority area on a larger scale or across different regions.

\section{Conclusions}

This study developed a high-priority WaSH research agenda based on broadly inclusive professional insight into learning needs during the period of SDG initiation, and characterized the status of research and learning dynamics among multi-sector WaSH professionals. Among targets of Goal 6, managing untreated wastewater and faecal sludge emerged as a top priority

This article is protected by copyright. All rights reserved. 
for knowledge generation and capacity building, forming a focal component of the research agenda. Several learning and training challenges became apparent, including difficulty interpreting conflicting sources of information and perceived exclusion of non-R\&L professionals from educational or training opportunities. Based on learning preferences, packaging WaSH information in multiple formats (e.g. both brief and detailed information with in-person interpretation) is recommended, as well as providing follow-up opportunities for peer interaction, debriefing, and troubleshooting. Findings showed consistent evidence of upward accountability to organizations that offer WaSH research or project funding, alongside inconsistent evidence of downward accountability to all stakeholders. Funding and financing were widespread determinants of WaSH activities, recommending broad integration of these topics into research and development efforts. All WaSH professionals, institutions, and networks should reflect on how they could best contribute to a culture of learning that would help achieve progress towards Goal 6.

\section{Acknowledgements}

This research was conducted in collaboration with Sanitation and Water for All (SWA), with special thanks to Clarissa Brocklehurst, Amanda Marlin, Alexandra Reis, and Sophie Thievenaz, as well as a volunteer working group from the SWA Research and Learning Constituency including: Sarah Dickin, Sara Marks, Patrick Moriarty, Eddy Perez, Erma Uytewaal, and Vidya Venkataramanan. We thank Osborn Kwena, Nur Aisyah Nasution, Jordan Dalton, and Teresa Edwards for their contributions to survey review. Funding for the study was generously provided by the University of North Carolina at Chapel Hill (UNC) Royster Society of Fellows and Center for European Studies, as well as the US National Institute of Environmental Health Sciences (grant T32ES007018).

First submitted July 2018

Final draft accepted November 2018

\section{References}

Bartram, J., Brocklehurst, C., Bradley, D., Muller, M., \& Evans, B. (2018). Policy review of the means of implementation targets and indicators for the sustainable development goal for water and sanitation. npj Clean Water, 1(1), 3. https://doi.org/10.1038/s41545-018-0003-0

Boyd, I. L. (2016). Take the long view. Nature Medicine, 22(1), 1-1. https://doi.org/10.1038/nm.4033

Brocklehurst, C. (2013). Outcomes of a meeting of senior finance ministry officials to discuss decisionmaking for WaSH: policy brief for the Steering Committee of the Sanitation and Water for All

This article is protected by copyright. All rights reserved. 
partnership. Chapel Hill, NC. Retrieved from https://waterinstitute.unc.edu/files/2014/11/FinanceMinistry-Decision-Making-for-WaSH_Policy-Brief.pdf

Bryant, J., Sanson-Fisher, R., Walsh, J., \& Stewart, J. (2014). Health research priority setting in selected high income countries: a narrative review of methods used and recommendations for future practice. Cost Effectiveness and Resource Allocation, 12(1), 23. https://doi.org/10.1186/1478-7547$12-23$

Cairney, P. (2016, 10 March). The politics of evidence-based policymaking. The Guardian. Retrieved from https://www.theguardian.com/science/political-science/2016/mar/10/the-politics-of-evidencebased-policymaking

Cash, D. W., Clark, W. C., Alcock, F., Dickson, N. M., Eckley, N., Guston, D. H., ... Mitchelll, R. B. (2003). Knowledge systems for sustainable development. PNAS, 100(14), 8086-8091. https://doi.org/10.1073/pnas.1231332100

Charmaz, K. (1996). The search for meanings-grounded theory. In J. A. Smith, R. Harré, \& L. Van Langenhove (Eds.), Rethinking Methods in Psychology (pp. 27-49). London: Sage Publications. https://doi.org/10.1016/B978-0-08-044894-7.01581-5

De Goede, J., van Bon-Martens, M., Mathijssen, J. J., Putters, K., \& Van Oers, H. (2012). Looking for interaction: quantitative measurement of research utilization by Dutch local health officials. Health Research Policy and Systems, 10(1), 9. https://doi.org/10.1186/1478-4505-10-9

DFID. (n.d.-a). Maximizing the benefits of water research to international development - What research programmers can do (SPLASH Briefing Note 1). Retrieved from http://splashera.net/downloads/SPLASH_Briefing_note_01.pdf

DFID. (n.d.-b). Maximizing the benefits of water research to international development - What researchers can do (SPLASH Briefing Note 2). Retrieved from http://splashera.net/downloads/SPLASH_Briefing_note_02.pdf

Doyle, J. (2005). Global priority setting for Cochrane systematic reviews of health promotion and public health research. Journal of Epidemiology \& Community Health, 59(3), 193-197. https://doi.org/10.1136/jech.2003.019547

Elder, M., Bengtsson, M., \& Akenji, L. (2016). An optimistic analysis of the means of implementation for sustainable development goals: Thinking about goals as means. Sustainability (Switzerland), 8(9). https://doi.org/10.3390/su8090962

European Commission. (2018). Responsible research \& innovation. Retrieved 29 June 2018, from https://ec.europa.eu/programmes/horizon2020/en/h2020-section/responsible-researchinnovation

Georgalakis, J. (2016, 5 April). Networks of academics help turn research into action. The Guardian. Retrieved from https://www.theguardian.com/global-development-professionalsnetwork/2016/apr/05/networks-of-academics-help-turn-research-into-action?CMP=share_btn_tw

Gupta, J. (2014). Global scientific assessments and environmental resource governance: towards a science-policy interface ladder. In M. Ambrus, K. Arts, E. Hey, \& H. Raulus (Eds.), The Role of 'Experts' in International and European Decision-Making Processes (p. 148-). Cambridge: Cambridge University Press.

This article is protected by copyright. All rights reserved. 
Hering, J. G. (2018). Implementation Science for the Environment. Environmental Science \& Technology, 52, 5555-5560. https://doi.org/10.1021/acs.est.8b00874

Hsieh, H.-F., \& Shannon, S. E. (2005). Three approaches to qualitative content analysis. Qualitative Health Research, 15(9), 1277-1288. https://doi.org/10.1177/1049732305276687

Huberman, M. (1994). Research utilization: the state of the art. Knowledge \& Policy, 7(4), 13-33. https://doi.org/Article

Hutton, G., \& Chase, C. (2016). The knowledge base for achieving the sustainable development goal targets on water supply, sanitation and hygiene. International Journal of Environmental Research and Public Health, 13(6), 1-35. https://doi.org/10.3390/ijerph13060536

Jiménez, A., Livsey, J., Åhlén, I., Scharp, C., \& Takane, M. (2018). Global assessment of accountability in water and sanitation services using GLAAS data. Water Alternatives, 11(2), 238-259.

Kim, H., Sefcik, J. S., \& Bradway, C. (2017). Characteristics of qualitative descriptive studies: a systematic review. Research in Nursing and Health, 40(1), 23-42. https://doi.org/10.1002/nur.21768

Kolsky, P. (n.d.). The process of applied research in the water and sanitation sector. Retrieved from http://www.lboro.ac.uk/garnet/actiwp1.html

Lewis, C. C., Weiner, B. J., Stanick, C., \& Fischer, S. M. (2015). Advancing implementation science through measure development and evaluation: A study protocol. Implementation Science, 10(1), 1-10. https://doi.org/10.1186/s13012-015-0287-0

May, C. R., Johnson, M., \& Finch, T. (2016). Implementation, context and complexity. Implementation Science, 11(1), 1-12. https://doi.org/10.1186/s13012-016-0506-3

Ménard, C., Jimenez, A., \& Tropp, H. (2018). Addressing the policy-implementation gaps in water services: the key role of meso-institutions. Water International, 43(1), 13-33.

https://doi.org/10.1080/02508060.2017.1405696

Nutley, S. M., Walter, I., \& Davies, H. T. O. (2007). Using evidence: how research can inform public services. Bristol: Policy Press.

Oldekop, J. A., Fontana, L. B., Grugel, J., Roughton, N., Adu-Ampong, E. A., Bird, G. K., ... Sutherland, W. J. (2016). 100 key research questions for the post-2015 development agenda. Development Policy Review, 34(1). https://doi.org/10.1111/dpr.12147

Pfadenhauer, L. M., Gerhardus, A., Mozygemba, K., Lysdahl, K. B., Booth, A., Hofmann, B., ... Rehfuess, E. (2017). Making sense of complexity in context and implementation: the Context and Implementation of Complex Interventions ( $\mathrm{ClCl}$ ) framework. Implementation Science, 12(21), 1-17. https://doi.org/10.1186/s13012-017-0552-5

Poch, M., Comas, J., Cortés, U., Sànchez-Marrè, M., \& Rodríguez-Roda, I. (2017). Crossing the death valley to transfer environmental decision support systems to the water market. Global Challenges, 1(3), 1700009. https://doi.org/10.1002/gch2.201700009

Rehfuess, E. A., Durao, S., Kyamanywa, P., Meerpohl, J. J., Young, T., \& Rohwer, A. (2016). An approach for setting evidence-based and stakeholder-informed research priorities in low- and middle-income countries. Bulletin of the World Health Organization, 94(4), 297-305.

This article is protected by copyright. All rights reserved. 
https://doi.org/10.2471/BLT.15.162966

Rose, D. C., Mukherjee, N., Simmons, B. I., Tew, E. R., Robertson, R. J., Vadrot, A. B. M., ... Sutherland, W. J. (2017). Policy windows for the environment: Tips for improving the uptake of scientific knowledge. Environmental Science and Policy. https://doi.org/10.1016/j.envsci.2017.07.013

Smith, L., An, J., \& Kawachi, I. (2013). Translating evidence to policy. In C. Guest, W. Ricciardi, I. Kawachi, \& I. Lang (Eds.), Oxford Handbook of Public Health Practice (pp. 276-282). Oxford: Oxford University Press.

SWA. (2018). About SWA. Retrieved June 29, 2018, from http://sanitationandwaterforall.org/about/

Tennant, J. P., Waldner, F., Jacques, D. C., Masuzzo, P., Collister, L. B., \& Hartgerink, C. H. J. (2016). The academic, economic and societal impacts of Open Access: an evidence-based review. F1000Research, 5, 632. https://doi.org/10.12688/f1000research.8460.3

Troeger, C., Forouzanfar, M., Rao, P. C., Khalil, I., Brown, A., Reiner Jr, R. C., ... Mokdad, A. H. (2017). Estimates of global, regional, and national morbidity, mortality, and aetiologies of diarrhoeal diseases: a systematic analysis for the Global Burden of Disease Study 2015. The Lancet Infectious Diseases, 3099(17), 1-40. https://doi.org/https://doi.org/10.1016/S1473-3099(17)30276-1

Tropp, H. (2007). Water governance: Trends and needs for new capacity development. Water Policy, 9(SUPPL. 2), 19-30. https://doi.org/10.2166/wp.2007.137

UN. (2015). The Millennium Development Goals Report. https://doi.org/978-92-1-101320-7

UN. (2018). Sustainable Development Goals: 17 goals to transform our world. Retrieved 29 June 2018, from http://www.un.org/sustainabledevelopment/water-and-sanitation/

UN General Assembly. (2015). Transforming our world: the 2030 Agenda for Sustainable Development (Vol. A/RES/70/1). https://doi.org/10.1007/s13398-014-0173-7.2

UN Water. (2018). Sustainable Development Goal 6 Synthesis Report on Water and Sanitation. Geneva.

UN Water, \& World Health Organization. (2017). Financing Universal Water, Sanitation and Hygiene Under the Sustainable Development Goals. UN-Water Global Analysis and Assessment of Sanitation and Drinking-Water (GLAAS) 2017 report. Geneva. Retrieved from http://apps.who.int/iris/bitstream/10665/254999/1/9789241512190-eng.pdf

Viergever, R. F., Olifson, S., Ghaffar, A., \& Terry, R. F. (2010). A checklist for health research priority setting: nine common themes of good practice. Health Research Policy and Systems, 8(1), 36. https://doi.org/10.1186/1478-4505-8-36

WASH Impact Network. (n.d.). Taking learning beyond the hotel conference room: How local WASH organizations implement new ideas. Retrieved June 29, 2018, from http://washinnovations.r4d.org/uploads/uploadsOneSheet.pdf

Wickremasinghe, D., Kuruvilla, S., Mays, N., \& Avan, B. I. (2016). Taking knowledge users' knowledge needs into account in health: An evidence synthesis framework. Health Policy and Planning, 31(4), 527-537. https://doi.org/10.1093/heapol/czv079

Wolf, J., Hunter, P. R., Cumming, O., Freeman, M. C., Clasen, T., Bartram, J., ... Prüss-Ustün, A. (2018). Impact of drinking water, sanitation and handwashing with soap on childhood diarrhoeal disease:

This article is protected by copyright. All rights reserved. 
updated meta-analysis and meta-regression. Tropical Medicine \& International Health, 23(5), 508525. https://doi.org/10.1111/tmi.13051

World Health Organization \& UNICEF. (2014). Progress on sanitation and drinking water: Joint Monitoring Programme update 2014. Geneva: World Health Organization.

\section{Appendix}

\section{A1. Full Questionnaire Transcript - SWA Country Partners}

(Questions did not appear numbered or lettered. Numbering and lettering is shown for reference only.)

\section{Welcome!}

Please select a language and click below to proceed to the questionnaire.

What? This questionnaire identifies water, sanitation, and hygiene (WasH) research priorities for achieving Sustainable Development Goal 6, and related communication preferences.

How? It has six sections and should take about 20 minutes to complete. Please answer questions based on your expertise, and leave blank any questions you do not feel comfortable answering. Responses are confidential and no personal information will be included in summary reports.

Who? The survey is being conducted by the Water Institute at The University of North Carolina, Chapel Hill (UNC) and the Research \& Learning constituency of Sanitation and Water for All (SWA). If you have any questions or concerns, please contact Karen Setty (ksetty@live.unc.edu).

--------page break--------

\section{SECTION 1: Introduction and Targets}

Background (Optional): Sustainable Development Goal 6 aims to "ensure availability and sustainable management of water and sanitation for all." Unlike previous global goals, it:

- Seeks access for all people to improved water sources and sanitation, regardless of wealth, geography, gender, social class, age, and disability.

- Considers safety and security to be an important part of water and sanitation service provision.

- Encourages both international cooperation and local community participation to help build capacity for domestic water and sanitation management.

This article is protected by copyright. All rights reserved. 
Q1 How confident are you in your knowledge/ability to work in each of the following target areas of Goal 6? (select one category for each row)

\begin{tabular}{|l|c|c|c|c|}
\hline & $\begin{array}{c}\text { Very } \\
\text { Confident }\end{array}$ & $\begin{array}{c}\text { Somewhat } \\
\text { Confident }\end{array}$ & Not Confident & Unsure \\
\hline A) Achieving universal access & 0 & 0 & 0 & 0 \\
B) Improving levels of service & 0 & 0 & 0 & 0 \\
C) Addressing inequalities & 0 & 0 & 0 & 0 \\
among sub-populations & 0 & 0 & 0 & 0 \\
$\begin{array}{l}\text { D) Ending open defecation } \\
\text { E) Managing untreated }\end{array}$ & 0 & 0 & 0 & 0 \\
wastewater & 0 & 0 & 0 & 0 \\
\hline $\begin{array}{l}\text { F) Building national capacity } \\
\text { G) Strengthening local } \\
\text { community participation }\end{array}$ & 0 & 0 & \\
\hline
\end{tabular}

Q2 Do you have any specific knowledge gaps or areas of concern related to achieving Goal 6? (please describe)

-------page break--------

\section{SECTION 2: Information for Decision-Making}

Q3 When you made WaSH-related decisions over the past six months, in which of these areas (related to governance and human resources) would more information have been helpful? (choose all that apply)

Accountability

Human resources

$\square$ Institutional change

- Participatory approaches

P Performance review

- Sector coordination/collaboration

Strategic planning/prioritization

- Other (please describe)

Q4 When you made WaSH-related decisions over the past six months, in which of these areas (related to finance and information systems) would more information have been helpful? (choose all that apply)

Affordability (e.g., subsidies, tariffs)

$\square$ Budgeting and costing

Cost-benefit analysis

This article is protected by copyright. All rights reserved. 


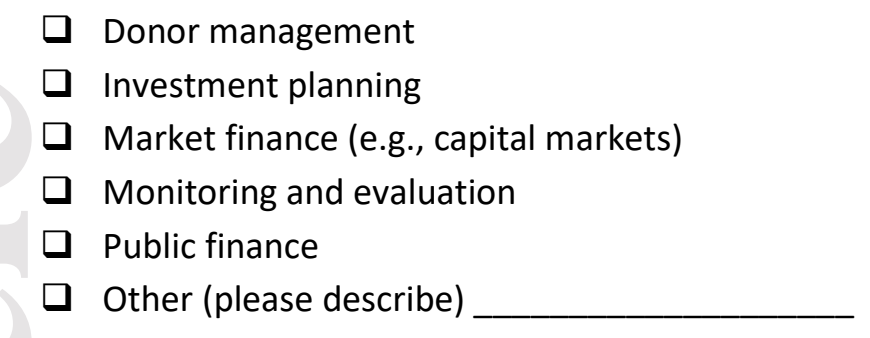

Q5 When you made WaSH-related decisions over the past six months, in which of these technical areas would more information have been helpful? (choose all that apply)

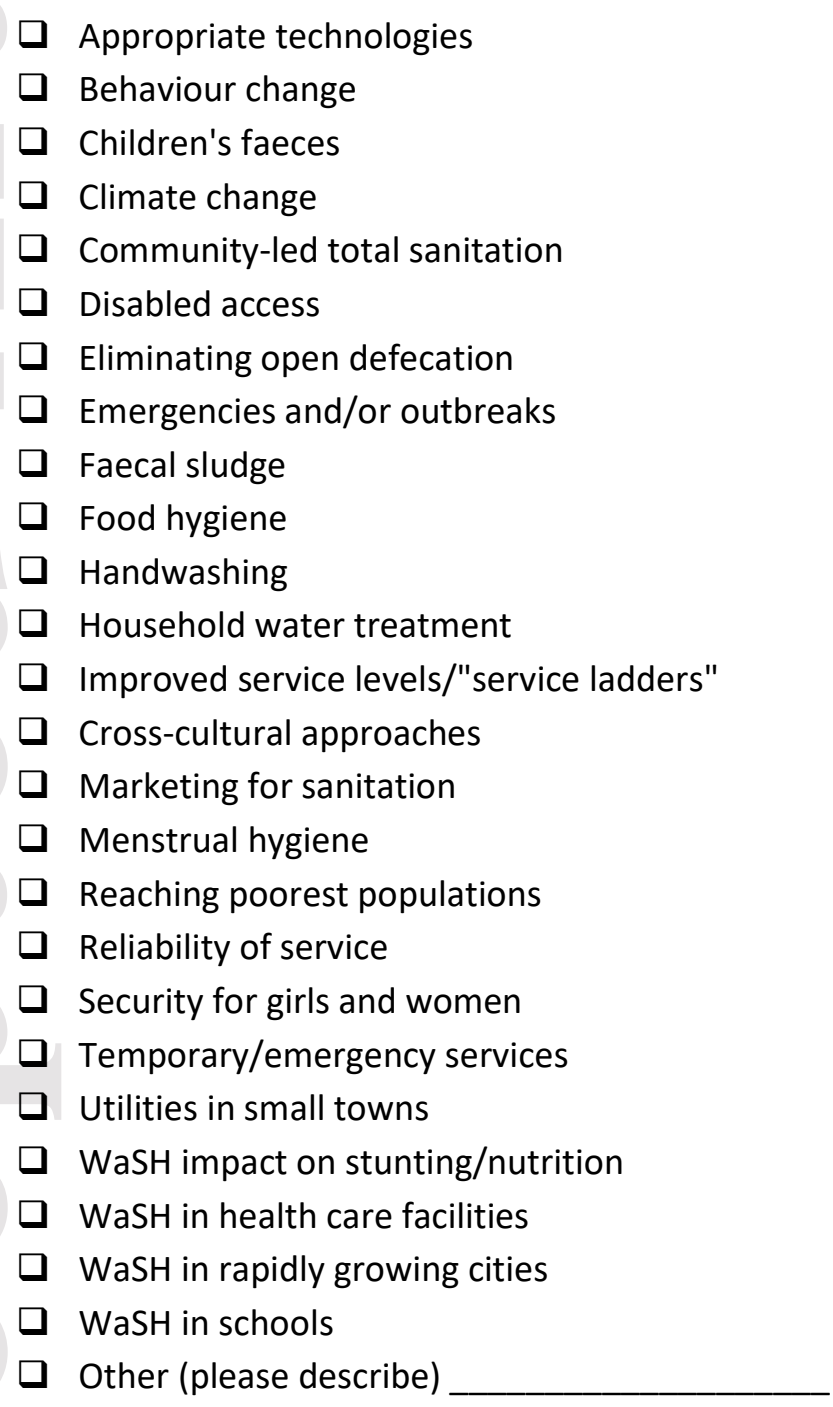

Q6 What was the primary topic of the WaSH-related decision (or decisions) you made over the past six months? (please describe)

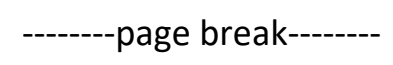

This article is protected by copyright. All rights reserved. 


\section{SECTION 3: Limitations to Decision-Making}

Q7 Which challenges did you experience when seeking information to make WaSH-related decision/s over the past six months? (choose all that apply)

Could not find/access information

Different sources of information conflicted

Information was not available for my region/situation

口 Information was not trustworthy/reliable

Information was outdated

- Information was too brief or general

Information was too lengthy or technical

$\square$ None

$\square$ Other (please describe)

Q8 Which other challenges did you experience when making WaSH-related decision/s over the past six months? (choose all that apply)

- Lacked adequate financial resources to consider alternative(s)

- Lacked cultural acceptance of alternative(s)

Lacked political traction for alternative(s)

- Lacked technological alternative(s)

Lacked time/capacity to evaluate alternative(s)

None

$\square$ Other (please describe)

Q9 Based on these limitations, what knowledge or information might have helped with your decision/s? (please describe)

--------page break--------

\section{SECTION 4: Approaches to Gathering Information}

Q10 Which organizations typically offer useful (e.g., accessible, understandable, relevant, and/or sufficient) information for addressing your WaSH-related questions? (choose all that apply)

Global monitoring organizations (e.g. JMP, GLAAS)

International civil society (non-governmental) organizations

L Local civil society or community organizations

Multilateral organizations (e.g., World Bank, WHO, UNICEF)

National monitoring agencies

news outlets

$\square$ Other government ministries or departments

Partnership networks (e.g., SWA)

This article is protected by copyright. All rights reserved. 
Private companies/consultants

$\square$ Universities (foreign)

U Universities (local)

$\square$ Other (please describe)

Q11 Which of these actions are typically useful for addressing your WaSH-related questions? (choose all that apply)

Ask a colleague/advisor in my office

- Call someone in my professional network

- Email a group of people (e.g., a listserv)

- Email someone in my professional network

- Initiate a new study/survey

$\square$ Organize a meeting or conference call

$\square$ Search the Internet

$\square$ Other (please describe)

Q12 Which of these informational formats are typically useful for addressing your WaSH-related questions? (choose all that apply)

\section{Book/report}

- Memorandum, bulletin, or flyer

- News (e.g., television, radio, newspaper)

$\square$ Online course/training module

- Online discussion forum

- Scientific or professional journal article

- Seminar/lecture

- Social media post (e.g., LinkedIn, Twitter)

Tool or worksheet

Webinar (virtual seminar/lecture)

Website

Other (please describe)

Q13 What would make the WaSH-related information you accessed over the past six months more useful? (choose all that apply)

An introduction (e.g., written, video)

$\square$ Discussion with my colleagues

Email, mail, or social media alerts

Executive summary/synopsis

Expert analysis/critique

$\square$ Reference to my country/situation

This article is protected by copyright. All rights reserved. 
- Translation for a non-specialist audience

$\square$ Translation into another language

$\square$ Other (please describe)

Q14 What new resources, if any, would you like to have available for addressing your WaSH-related questions? (please describe)

--------page break--------

\section{SECTION 5: Learning and Training Needs}

Q15 Which challenges did you experience when seeking WaSH-related training or educational opportunities over the past six months? (choose all that apply)

Did not receive notice/invitation

$\square$ None offered

Not relevant to my region/situation

Too busy to participate

$\square$ Too expensive

$\square$ None

$\square$ Other (please describe)

Q16 How willing would you be to interact with WaSH researchers (e.g., to help plan studies and share new information)? (select one)

V Very willing

O Somewhat willing

O Somewhat unwilling

O Extremely unwilling

\section{Q17 Other Comments}

Do you have any other advice or comments? (if so, please describe) page break--------

\section{SECTION 6: Your Professional Background}

Q18 What is your educational specialization? (can select more than one)

Business/Economics/Finance

$\square$ Engineering

Humanities (e.g., Languages, Geography)

u Journalism

口 Political Science

Medicine/Public Health

This article is protected by copyright. All rights reserved. 
Natural Science/Mathematics

- Sociology/Anthropology

$\square$ Other (please describe)

Q19 Which category best describes your current workplace? (select one)

Ministry of Finance

O Ministry of Health

O Ministry of Water

Other (please describe)

Q20 Which category best describes your current professional responsibilities? (select one)

O Minister

O Adviser in minister's office

Director/manager

O Technical staff

Other (please describe)

--------page break--------

\section{Thank you for completing this questionnaire!}

Your feedback is important to helping us understand evidence needs to achieve Goal 6, ensuring availability and sustainable management of water and sanitation for all.

The following steps are optional. When ready, please click below to submit your responses.

Q21 May we contact you for a short follow-up interview (about 30 minutes)? If so, please enter your first name and preferred contact method. (Note: Information will be kept confidential.)

First name

E-mail address

Phone

SkypeTM

Q22 Would you like to nominate a WaSH-related research and learning institution/s in your country to join the Sanitation and Water for All partnership? (Note: Information will only be used by SWA to reach out to potential new partners.)

Institution

Location

Name of contact (if available)

Contact information (if available)

This article is protected by copyright. All rights reserved. 


\section{A2. Full Questionnaire Transcript - SWA Research and Learning Partners}

(Questions did not appear numbered or lettered. Numbering and lettering is shown for reference only.)

\section{Welcome!}

Please click below to proceed to the questionnaire.

What? This questionnaire identifies water, sanitation, and hygiene (WasH) research priorities for achieving Sustainable Development Goal 6, and related communication preferences.

How? It has five sections and should take about 15 minutes to complete. Please answer questions based on your expertise, and leave blank any questions you do not feel comfortable answering. Responses are confidential and no personal information will be included in summary reports.

Who? The survey is being conducted by the Water Institute at The University of North Carolina, Chapel Hill (UNC) and the Research \& Learning constituency of Sanitation and Water for All (SWA). If you have any questions or concerns, please contact Karen Setty (ksetty@live.unc.edu).

\section{--------page break--------}

\section{SECTION 1: Introduction and Targets}

Background (Optional): Sustainable Development Goal 6 aims to "ensure availability and sustainable management of water and sanitation for all." Unlike previous global goals, it:

- Seeks access for all people to improved water sources and sanitation, regardless of wealth, geography, gender, social class, age, and disability.

- Considers safety and security to be an important part of water and sanitation service provision.

- Encourages both international cooperation and local community participation to help build capacity for domestic water and sanitation management.

This article is protected by copyright. All rights reserved. 
Q1 How confident are you in your knowledge/ability to work in each of the following target areas of Goal 6? (select one category for each row)

\begin{tabular}{|l|c|c|c|c|}
\hline & $\begin{array}{c}\text { Very } \\
\text { Confident }\end{array}$ & $\begin{array}{c}\text { Somewhat } \\
\text { Confident }\end{array}$ & Not Confident & Unsure \\
\hline A) Achieving universal access & 0 & 0 & 0 & 0 \\
B) Improving levels of service & 0 & 0 & 0 & 0 \\
C) Addressing inequalities & 0 & 0 & 0 & 0 \\
among sub-populations & 0 & 0 & 0 & 0 \\
$\begin{array}{l}\text { D) Ending open defecation } \\
\text { E) Managing untreated }\end{array}$ & 0 & 0 & 0 & 0 \\
wastewater & 0 & 0 & 0 & 0 \\
\hline $\begin{array}{l}\text { F) Building national capacity } \\
\text { G) Strengthening local } \\
\text { community participation }\end{array}$ & 0 & 0 & \\
\hline
\end{tabular}

Q2 Do you have any specific knowledge gaps or areas of concern related to Goal 6? (please describe)

$$
\text { --------page break-------- }
$$

\section{SECTION 2: Recent and Future WaSH Research Needs}

Q3 In which of these areas (related to governance and human resources) would more information have been helpful to your work over the past six months? (choose all that apply)
a Accountability
- Human resources
$\square$ Institutional change
口 Participatory approaches
$\square$ Performance review
- Sector coordination/collaboration
Strategic planning/prioritization
$\square$ Other (please describe)

Q4 In which of these areas (related to finance and information systems) would more information have been helpful to your work over the past six months? (choose all that apply)

Affordability (e.g., subsidies, tariffs)

Budgeting and costing

- Cost-benefit analysis

Donor management

This article is protected by copyright. All rights reserved. 
Investment planning

- Market finance (e.g., capital markets)

Monitoring and evaluation

$\square$ Public finance

$\square$ Other (please describe)

Q5 In which of these technical areas would more information have been helpful to your work over the past six months? (choose all that apply)

Appropriate technologies

$\square$ Behaviour change

- Children's faeces

- Climate change

- Community-led total sanitation

$\square$ Disabled access

- Eliminating open defecation

$\square$ Emergencies and/or outbreaks

Faecal sludge

Food hygiene

․ Handwashing

- Household water treatment

口 Improved service levels/"service ladders"

$\square$ Cross-cultural approaches

- Marketing for sanitation

- Menstrual hygiene

$\square$ Reaching poorest populations

Reliability of service

- Security for girls and women

a Temporary/emergency services

- Utilities in small towns

W WaSH impact on stunting/nutrition

WaSH in health care facilities

WaSH in rapidly growing cities

WaSH in schools

$\square$ Other (please describe)

Q6 On what primary topics did you seek WaSH-related information over the past six months? (please describe)

Q7 From your perspective, what will be the most pressing WaSH-related research needs in coming years? (please describe)

This article is protected by copyright. All rights reserved. 


\section{SECTION 3: Communication and Interaction}

Q8 Which organizations typically sponsor your research or educational activities? (choose all that apply)

C Companies or corporations

$\square$ Foundations or aid organizations

$\square$ Government agencies (domestic/federal)

Government agencies (domestic/state or regional)

$\square$ Government agencies (foreign)

- Multilateral organizations (e.g., World Bank, WHO, UNICEF)

P Private donors/individuals

$\square$ Other (please describe)

Q9 If you submit proposals for funding, are the requests for proposals typically open-ended or topicspecific? (choose one)

V Very open-ended

O Somewhat open-ended

Somewhat topic-specific

Very topic-specific

Not applicable

Q10 Who typically disseminates the outcomes of your research or educational activities? (choose all that apply)

D Donors

$\square$ Independent media

口 Internal communications department

? Partnership networks

- Scientific community

- Stakeholders

$\square$ Other (please describe)

Q11 How often are stakeholders involved in your research or educational activities? (choose one)

O $>90 \%$ of the time

O $70-90 \%$ of the time

O $30-70 \%$ of the time

O $10-30 \%$ of the time

O $<10 \%$ of the time

O Unsure

This article is protected by copyright. All rights reserved. 
Q12 At which stages are stakeholders typically involved in your research or educational activities?

(choose all that apply)
$\square$ Scoping
$\square$ Design
口 Implementation
a Analysis/Interpretation
Dissemination
Other (please describe)

Q13 What would help better match your research and educational activities to the needs of end users? (please describe)

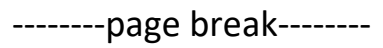

\section{SECTION 4: Research and Learning Challenges}

Q14 Which challenges did you experience when seeking WaSH-related information over the past six months? (choose all that apply)

Could not find/access information

$\square$ Different sources of information conflicted

Information was not available for my region/situation

$\square$ Information was not trustworthy/reliable

$\square$ Information was outdated

Information was too brief or general

Information was too lengthy or technical

$\square$ None

$\square$ Other (please describe)

Q15 Which challenges did you experience when seeking WaSH-related training or educational opportunities over the past six months? (choose all that apply)

Did not receive notice/invitation

$\square$ None offered

Not relevant to my region/situation

Too busy to participate

Too expensive

$\square$ None

$\square$ Other (please describe)

Q16 What obstacles might affect your ability to undertake research or educational activities? (choose all that apply)

This article is protected by copyright. All rights reserved. 
Broader political climate

Lack of funding

Lack of interest among higher-ups

- Lack of partnership opportunities

L Lack of technical or human resources

L Lack of stakeholder buy-in

O Other (please describe)

Q17 What new resources, if any, would help to specifically address these needs? (please describe)

\section{Q18 Other Comments}

Do you have any other advice or comments? (if so, please describe)

--------page break--------

\section{SECTION 5: Your Professional Background}

Q19 What is your educational specialization? (can select more than one)

B Business/Economics/Finance

Engineering

Humanities (e.g., Languages, Geography)

u Journalism

$\square$ Political Science

- Medicine/Public Health

- Natural Science/Mathematics

- Sociology/Anthropology

$\square$ Other (please describe)

Q20 What is the scale or scope of your current workplace? (select one)

Local/regional

O National

O International

Other (please describe)

Q21 Which category best describes your current professional responsibilities? (select one)

O Director/administrator

Project manager

Research/technical staff

Other (please describe)

Q22 Did you participate in the Research and Learning survey working group? (select one)

This article is protected by copyright. All rights reserved. 
O Yes

O No

O Unsure

\section{--------page break--------}

\section{Thank you for completing this questionnaire!}

Your feedback is important to helping us understand evidence needs to achieve Goal 6, ensuring availability and sustainable management of water and sanitation for all.

The following steps are optional. When ready, please click below to submit your responses.

Q23 May we contact you for a short follow-up interview (about 30 minutes)? If so, please enter your first name and preferred contact method. (Note: Information will be kept confidential.)

First name

E-mail address

Phone

Skype $^{\mathrm{TM}}$

Q24 Would you like to nominate a WaSH-related research and learning institution/s to join the Sanitation and Water for All partnership? (Note: Information will only be used by SWA to reach out to potential new partners.)

Institution

Location

Name of contact (if available)

Contact information (if available)

This article is protected by copyright. All rights reserved. 


\section{A3. Full Questionnaire Transcript - All Other SWA Partners}

(Questions did not appear numbered or lettered. Numbering and lettering is shown for reference only.)

\section{Welcome!}

Please select a language and click below to proceed to the questionnaire.

What? This questionnaire identifies water, sanitation, and hygiene $(\mathrm{WasH})$ research priorities for achieving Sustainable Development Goal 6, and related communication preferences.

How? It has six sections and should take about 20 minutes to complete. Please answer questions based on your expertise, and leave blank any questions you do not feel comfortable answering. Responses are confidential and no personal information will be included in summary reports.

Who? The survey is being conducted by the Water Institute at The University of North Carolina, Chapel Hill (UNC) and the Research \& Learning constituency of Sanitation and Water for All (SWA). If you have any questions or concerns, please contact Karen Setty (ksetty@live.unc.edu).

$$
\text { -page break-------- }
$$

\section{SECTION 1: Introduction and Targets}

Background (Optional): Sustainable Development Goal 6 aims to "ensure availability and sustainable management of water and sanitation for all." Unlike previous global goals, it:

- Seeks access for all people to improved water sources and sanitation, regardless of wealth, geography, gender, social class, age, and disability.

- Considers safety and security to be an important part of water and sanitation service provision.

- Encourages both international cooperation and local community participation to help build capacity for domestic water and sanitation management.

Q1 How confident are you in your knowledge/ability to work in each of the following target areas of Goal 6 ? (select one category for each row)

\begin{tabular}{|l|c|c|c|c|}
\hline & $\begin{array}{c}\text { Very } \\
\text { Confident }\end{array}$ & $\begin{array}{c}\text { Somewhat } \\
\text { Confident }\end{array}$ & Not Confident & Unsure \\
\hline A) Achieving universal access & 0 & 0 & 0 & 0 \\
B) Improving levels of service & 0 & 0 & 0 & 0 \\
$\begin{array}{l}\text { C) Addressing inequalities } \\
\text { among sub-populations }\end{array}$ & 0 & 0 & 0 & 0 \\
$\begin{array}{l}\text { D) Ending open defecation } \\
\text { E) Managing untreated }\end{array}$ & 0 & 0 & 0 & 0 \\
\hline wastewater & 0 & 0 & \\
\hline
\end{tabular}

This article is protected by copyright. All rights reserved. 


\begin{tabular}{|l|c|c|c|c|}
\hline $\begin{array}{l}\text { F) Building national capacity } \\
\text { G) Strengthening local } \\
\text { community participation }\end{array}$ & 0 & 0 & 0 & 0 \\
\hline
\end{tabular}

Q2 Do you have any specific knowledge gaps or areas of concern related to achieving Goal 6? (please describe)

-------page break--------

\section{SECTION 2: WaSH Information Needs}

Q3 In which of these areas (related to governance and human resources) would more information have been helpful to your work over the past six months? (choose all that apply)
a Accountability
Human resources
Institutional change
Participatory approaches
- Performance review
- Sector coordination/collaboration
- Strategic planning/prioritization
Other (please describe)

Q4 In which of these areas (related to finance and information systems) would more information have been helpful to your work over the past six months? (choose all that apply)
Affordability (e.g., subsidies, tariffs)
Budgeting and costing
- Cost-benefit analysis
$\square$ Donor management
- Investment planning
Market finance (e.g., capital markets)
M Monitoring and evaluation
a Public finance
$\square$ Other (please describe)

Q5 In which of these technical areas would more information have been helpful to your work over the past six months? (choose all that apply)

Appropriate technologies

a Behaviour change

Children's faeces

This article is protected by copyright. All rights reserved. 
Climate change

- Community-led total sanitation

- Disabled access

- Eliminating open defecation

Emergencies and/or outbreaks

Faecal sludge

a Food hygiene

- Handwashing

Household water treatment

口 Improved service levels/"service ladders"

a Cross-cultural approaches

Marketing for sanitation

Menstrual hygiene

- Reaching poorest populations

Reliability of service

- Security for girls and women

Temporary/emergency services

U Utilities in small towns

- WaSH impact on stunting/nutrition

W WaSH in health care facilities

WaSH in rapidly growing cities

WaSH in schools

$\square$ Other (please describe)

Q6 On what primary topics did you seek WaSH-related information over the past six months? (please describe)

Q7 From your perspective, what will be the most pressing WaSH-related evidence needs over the next several years? (please describe)

--------page break--------

\section{SECTION 3: Information Gathering Challenges}

Q8 What obstacles might affect your ability to undertake WaSH-related activities? (choose all that apply)

Broader political climate

Lack of funding

Lack of interest among higher-ups

- Lack of partnership opportunities

$\square$ Lack of technical or human resources

Lack of stakeholder buy-in

$\square$ Other (please describe)

This article is protected by copyright. All rights reserved. 
Q9 Which challenges did you experience when seeking WaSH-related information over the past six months? (choose all that apply)
Could not find/access information
$\square$ Different sources of information conflicted
I Information was not available for my region/situation
I Information was not trustworthy/reliable
$\square$ Information was outdated
Information was too brief or general
I Information was too lengthy or technical
None
$\square$ Other (please describe)

Q10 What would make the WaSH-related information you accessed over the past six months more useful? (choose all that apply)

An introduction (e.g., written, video)

$\square$ Discussion with my colleagues

Email, mail, or social media alerts

Executive summary/synopsis

- Expert analysis/critique

Reference to my country/situation

- Translation for a non-specialist audience

Translation into another language

O Other (please describe)

Q11 Which challenges did you experience when seeking WaSH-related training or educational opportunities over the past six months? (choose all that apply)

Did not receive notice/invitation

None offered

Not relevant to my region/situation

Too busy to participate

Too expensive

None

$\square$ Other (please describe)

Q12 What new informational or training resources, if any, would you like to have available for addressing WaSH-related questions? (please describe)

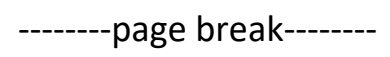

This article is protected by copyright. All rights reserved. 


\section{SECTION 4: Funding Activities}

Q13 If your organization funds WaSH research or activities, which types of organizations do you typically sponsor? (choose all that apply)

Civil society organizations

$\square$ Community-based organizations

$\square$ Government agencies (federal)

$\square$ Government agencies (state or regional)

P Private companies or corporations

U Universities

Other (please describe)

Not applicable

Q14 If your organization funds WaSH research or activities, are the requests for proposals typically open-ended or topic-specific? (choose one)

O Very open-ended

Somewhat open-ended

Somewhat topic-specific

Very topic-specific

Other (please describe)

Not applicable

Q15 If your organization funds WaSH research or activities, why might you decline to fund a certain activity? (choose all that apply)

Broader political climate

Doesn't match interests of donors/constituents

$\square$ Doesn't match organizational directions

- Lack of plans for partnership/stakeholder involvement

Lack of knowledge/trust in applicant's organization

$\square$ Lack of scientific rigor or pre-proposal planning

Other (please describe)

Not applicable

Q16 What would help better match your organization's WaSH-related work to existing needs? (please describe)

--------page break--------

\section{SECTION 5: Communication and Interactions}

Q17 How often are stakeholders involved in your WaSH-related work? (choose one)

This article is protected by copyright. All rights reserved. 

O $>90 \%$ of the time
O $70-90 \%$ of the time
O $30-70 \%$ of the time
O $10-30 \%$ of the time
O $<10 \%$ of the time
O Unsure

Q18 At which stages are stakeholders typically involved in your WaSH-related work? (choose all that apply)
Scoping
$\square$ Design
- Implementation
a Analysis/Interpretation
- Dissemination
Other (please describe)

Q19 Who typically disseminates the outcomes of your WaSH-related work? (choose all that apply)

Donors

Independent media

- Internal communications department

- Partnership networks

a Scientific community

- Stakeholders

$\square$ Other (please describe)

Q20 How often do you interact with WaSH researchers (e.g., to help plan studies and share new information)? (select one)

Once a week

Once a month

Once every few months

O Once a year

Other (please describe)

\section{Q21 Other Comments}

Do you have any other advice or comments? (if so, please describe)

$$
\text { --------page break-------- }
$$

\section{SECTION 6: Your Professional Background}

This article is protected by copyright. All rights reserved. 
Q22 What is your educational specialization? (can select more than one)

Business/Economics/Finance

$\square$ Engineering

Humanities (e.g., Languages, Geography)

u Journalism

口 Political Science

Medicine/Public Health

- Natural Science/Mathematics

- Sociology/Anthropology

$\square$ Other (please describe)

Q23 Which category best describes your current workplace? (select one)

Civil society organization (or network)

Community-based organization (or network)

Oxternal support or funding agency

Private sector organization (or network)

Other (please describe)

Q24 Which category best describes your current professional responsibilities? (select one)

Director/administrator

Project manager

Technical staff

Other (please describe)

--------page break--------

\section{Thank you for completing this questionnaire!}

Your feedback is important to helping us understand evidence needs to achieve Goal 6, ensuring availability and sustainable management of water and sanitation for all.

The following steps are optional. When ready, please click below to submit your responses.

Q25 May we contact you for a short follow-up interview (about 30 minutes)? If so, please enter your first name and preferred contact method. (Note: Information will be kept confidential.)

First name

E-mail address

Phone

SkypeTM

This article is protected by copyright. All rights reserved. 
Q26 Would you like to nominate a WaSH-related research and learning institution/s to join the Sanitation and Water for All partnership? (Note: Information will only be used by SWA to reach out to potential new partners.)

Institution

Location

Name of contact (if available)

Contact information (if available)

\section{A4. Research Agenda}

1. Managing untreated wastewater/faecal sludge (Q1, Rank 1; Q2, Rank 1)

a. Strategic planning/prioritization (Q3, Rank 1)

i. Which approaches to safe wastewater faecal sludge disposal or geographical/population priorities will have the greatest impact on reducing faecal pollution and disease transmission by 2030 ?

b. Monitoring and evaluation (Q4, Rank 1)

i. Can changes in global raw sewage or faecal discharge be quantified over time? What are the key drivers of this change?

c. Affordability (e.g., subsidies, tariffs) (Q4, Rank 2)

i. What cost-recovery mechanisms and demonstrated business models (including cost scenarios) are available to cities or communities interested in tackling untreated wastewater or faecal sludge discharges? (Q7)

ii. What payment mechanisms or payment options engender the greatest buy-in for new sanitation services? How can payment for sanitation services best be stabilized over time?

d. Appropriate technologies (Q5, Rank 2)

i. Are adequate decision support tools in place to determine the best wastewater treatment scheme for a given location, whether traditional or unconventional? What are the key decision criteria? Have such solutions been reliably costed?

e. Sustainable/ecological solutions (Q7, Rank 3)

i. How can nutrients in wastewater/faecal sludge safely be redistributed and reused for crop production? (Q6)

f. Resilience/security/climate change (Q7, Rank 3)

i. Can risk management approaches such as sanitation safety planning help control environmental impacts from accidental sewage/sewerage release?

2. Ending open defecation (Q1, Rank 2)

a. Appropriate technologies (Q5, Rank 2)

i. Which marketing or behaviour change approaches have been the most successful and why might they succeed or fail in a different context? (Q7)

b. Monitoring and evaluation (Q4, Rank 1)

i. What is the nature and magnitude of the links between WaSH improvements and community health status? $(\mathrm{Q} 6, \mathrm{Q} 7)$

This article is protected by copyright. All rights reserved. 
3. Addressing inequalities among sub-populations (Q1, Rank 3)

a. [Gender] Equality/non-discrimination (Q7, Rank 1)

i. What are the public health and economic benefits of menstrual hygiene management? (Q7) How can stigmas about menstrual hygiene management be tackled?

b. Equality/non-discrimination (Q7, Rank 1)

i. Which individuals/populations experience a disproportional burden from negative outcomes linked to WaSH-related stunting? (Q7) Can better prevention and treatment mechanisms be developed to reduce these impacts?

c. Monitoring and evaluation (Q4, Rank 1)

i. Can disaggregated data be generated to ensure equality, non-discrimination, and targeting of services? (Q7)

4. Achieving universal access (Q1, Rank 4)

a. Sector coordination/collaboration (Q3, Rank 2)

i. Are government accountability measures for WaSH achievements working? Are any countries falling through the cracks?

ii. What bottlenecks prevent actors from putting collaborative behaviours into practice? (Q7)

b. WaSH in institutions and public spaces (Q7, Rank 2)

i. What options are available for increasing access to improved public sanitation facilities (including menstrual hygiene management) in heavily populated areas versus more remote, rural areas? (Q7)

c. Universal access/remote areas (Q7, Rank 3)

i. What conventional or unconventional WaSH options are available for serving remote populations? (Q7) Have any been proven more successful than others? What decision criteria are recommended?

5. Building national capacity (Q1, Rank 5; Q2, Rank 3)

a. Sector coordination/collaboration (Q3, Rank 2)

i. How can WaSH targets be integrated with programming on other targets, such as food and energy security? (Q7)

b. National policy/strategy/human rights law (Q6, Rank 1)

i. Are emergency management or response plans in place to address recent or future WaSH-related disease epidemics? (Q6)

6. Financing (Q2, Rank 2)

a. Equality/non-discrimination (Q7, Rank 1)

i. How should WaSH services be financed in the case of extremely poor, marginalized, or transient peoples?

b. Resilience/security/climate change (Q7, Rank 3)

i. Given economic, political, and climate uncertainty, what financing options or portfolio of options are most resilient? How can dips or lags in financing best be weathered?

7. Improving levels of service (Q1, Rank 6)

a. Water quality/safety (Q6, Rank 3)

This article is protected by copyright. All rights reserved. 
i. What benefits can be gained from proactive risk management approaches such as water safety planning? (Q6)

b. Equality/non-discrimination (Q7, Rank 1)

i. Where can we find successful case studies of scaling up high quality WaSH services in an equitable manner? How were these services delivered? (Q7)

c. Monitoring and evaluation (Q4, Rank 1)

i. How might demographic trends hinder the ability to maintain and improve WaSH service levels? (Q7)

ii. What is the long-term cost-effectiveness and health impact of communal water points versus in-home piped access? (Q7)

8. Ecosystem sustainability/resource conservation (Q2, Rank 4)

a. Strategic planning/prioritization (Q3, Rank 1)

i. Do all new WaSH services consider ecological sustainability, including different scenarios of climate change? If not, why not? (Q7)

b. Sustainable/ecological solutions (Q7, Rank 3)

i. How can existing WaSH facilities and water/wastewater treatment processes be retrofit to enhance efficiency and reduce environmental impacts?

9. Strengthening local community participation (Q1, Rank 7)

a. Equality/non-discrimination (Q7, Rank 1)

i. How can communities include diverse citizens in WaSH decisions, especially young people and women? (Q7) What are the benefits of diversity and inclusion?

b. Reaching poorest populations (Q5, Rank 1 )

i. What behaviour change mechanisms work across diverse slum environments? (Q7)

This article is protected by copyright. All rights reserved. 